\title{
A survey of human shoulder functional kinematic representations
}

\author{
Rakesh Krishnan $^{1,2,4}$ • Niclas Björsell ${ }^{1}$ Elena M. Gutierrez-Farewik ${ }^{3,4}$ • Christian Smith ${ }^{2,4}$
}

Received: 26 June 2017 / Accepted: 17 December 2017 / Published online: 26 October 2018

(c) The Author(s) 2018

\begin{abstract}
In this survey, we review the field of human shoulder functional kinematic representations. The central question of this review is to evaluate whether the current approaches in shoulder kinematics can meet the high-reliability computational challenge. This challenge is posed by applications such as robot-assisted rehabilitation. Currently, the role of kinematic representations in such applications has been mostly overlooked. Therefore, we have systematically searched and summarised the existing literature on shoulder kinematics. The shoulder is an important functional joint, and its large range of motion (ROM) poses several mathematical and practical challenges. Frequently, in kinematic analysis, the role of the shoulder articulation is approximated to a ball-and-socket joint. Following the high-reliability computational challenge, our review challenges this inappropriate use of reductionism. Therefore, we propose that this challenge could be met by kinematic representations, that are redundant, that use an active interpretation and that emphasise on functional understanding.
\end{abstract}

Keywords Kinematics · Robot-assisted rehabilitation · Human movement understanding · Human-robot interaction · Shoulder

\section{Introduction}

Human movement is in the spotlight as researchers attempt to design and successfully interface machines with humans. Importantly, the success of these devices relies on the interaction design. Equivalently, the reliable parameterisation of human movement is important in generating computer models in biomechanics. Although human movement kinematics

Rakesh Krishnan

rkth@kth.se

Niclas Björsell

niclas.bjorsell@hig.se

Elena M. Gutierrez-Farewik

lanie@mech.kth.se

Christian Smith

ccs@kth.se

1 Department of Electronics, Mathematics and Natural Sciences, University of Gävle, Gävle, Sweden

2 Robotics, Perception and Learning (RPL), School of Computer Science and Communication, Royal Institute of Technology (KTH), Stockholm, Sweden

3 KTH Engineering Sciences, Mechanics, Royal Institute of Technology (KTH), Stockholm, Sweden

4 BioMEx Center, Royal Institute of Technology (KTH), Stockholm, Sweden is of central importance in both these fields, the underlying level of abstraction, detail and purpose are diverse. Here, the fundamental difference lies in the underlying mechanisms. Robot motion can often be modelled repeatably using simplified laws of physics, such as pure rotational joints. In contrast, such laws cannot completely and reliably describe biological motion [1]. Therefore, this review aims not only to classify and summarise the existing literature but also to draw attention towards several knowledge gaps in movement kinematics in general and shoulder kinematics in particular.

Need for a review Reviewing shoulder kinematics is challenging due to the functional complexity [2], diversity of objectives, diversity in kinematic representations and protocols used in the literature [3-5]. Traditionally, in biomechanics, 3D motion analysis has been used in the qualitative and quantitative evaluation of biological health [6]. In human motor control, kinematics is used to understand the underlying neural policy [3]. Although human movement has been studied in biomechanics and motor control for several decades, it is only recently that human movement has emerged as a mainstream research topic in robotics [7, 8]. Current trends in robotics research are moving towards the concept of human-centric models. Such models are based on a functional understanding of 
humans and have the potential to act as templates for developing technology that can improve the end goals of a rehabilitation intervention [9].

Despite this need, there is a lack of up-to-date literature on functional shoulder kinematics. To the best of our knowledge, the only available review on this topic was published by Maurel and Thalmann [10], in which the main focus was on dynamic simulation. Note that in such applications, the interest is in describing and reproducing observed movements. Such an analysis is not of immediate help in human-robot interaction (HRI).

Role of movement kinematics in HRI In HRI, a key bottleneck exists as to how the robot can understand the movement cues from the human user [11]. Without this essential knowledge, the robot cannot operate in synchrony with the human, thus raising concerns of usability and safety [11]. Estimating human intention from the brain signals or muscles is computationally daunting. However, kinematics has the potential to be the primary level of understanding intention because the higher we climb the ladder of motor hierarchies, the greater the level of abstraction of the intention signals is [1]. However, even if kinematics can be used as an implicit command, there is no agreement on the mathematical framework that is most suitable for this purpose [12-18].

Currently, the majority of HRI review papers cover only the physical aspects [18-20]. In fact, it is the cognitive interaction that in turn drives the physical HRI [21]. Mainly, in cognitive HRI (cHRI), such as in robot-assisted rehabilitation, there is an active knowledge-based two-way dialogue between the human user and the robot [22]. In such an advanced HRI problem, kinematics is essential in the steps of intention modelling, design, reasoning, planning, execution and user evaluation [9, 21, 23-25].

In HRI, replicating 3D upper arm kinematics is a challenge $[12,13]$. Understanding the principles of the human upper limb poses a non-trivial computational problem; overall, there is a lack of reliable tools and evaluation metrics for this purpose [3, 12, 14]. In recent years, there have been strong criticisms against the validity of "the promise of robot-assisted rehabilitation" (see [26]). Thus far, robotassisted rehabilitation has been able to demonstrate its real benefits only at a kinematic level [27]. Despite these promising results, many of the existing robotic solutions oversimplify the upper limb kinematics [23].

Aims and scope In this review, we aim to summarise the existing literature on functional shoulder kinematics. Because this topic is interdisciplinary, we attempt to integrate the knowledge from several diverse research communities. Importantly, in rehabilitation technology, it is expected that the robotic solutions yield consistent results [28]. Therefore, it is a pre-requisite that the computational framework which drives the HRI be highly reliable [28]. In the future, we hope that the findings of our review will be translated into effective robot-assisted rehabilitative solutions like exoskeletons. Primarily, this technology aims for functional compensation or assistance $[29,30]$. Therefore, we limit our review to papers addressing functional shoulder kinematics.

To clarify, a "functional shoulder" is gauged by painlessness, mobility, a harmonious motion pattern between the joints, and stability [31,32]. In this review, function implies that the emphasis is on the day-to-day use of the shoulder. Although the focus is on functional kinematic representations, we briefly mention other existing literatures wherever relevant.

Role of kinematic representations Kinematic representations can be thought of as mathematical structures that model the movement of interest. Different kinematic representations are helpful in extending and updating our understanding of various underlying mechanisms of the neuromuscular system [33]. Note that their choice is not unique; rather, it is context- or application-specific [34, 35].

What is the high-reliability requirement in shoulder kinematics? The answer can be divided possibly into three parts. First, when using kinematic representations, numerical singularities pose the problem of ambiguity, which in turn might lead to ambiguity in the volitional command that drives HRI. Such a situation must be avoided at any cost. Therefore, a lack of numerical singularities is paramount.

Second, when movement variability is used to understand the underlying neural policy, computational reliability is very important. A compromise in this regard can undermine the conclusions of the study [36, 37]. Mainly, for the same movement, a different choice of kinematic representations can result in conflicting results [38]. This fact is often overlooked in robotics. In robotics, interest has been limited to finding a consistent and repeatable solution with no element of causation or reasoning in mind $[8,39]$.

Third, the mathematical representation must faithfully follow the physiological kinematics [37]. A violation of this requirement results in a representational mismatch. This error is usually small for joints with small range of motion (ROM). However, because the shoulder is one of the joints with the largest ROM, this error would be very high. Therefore, we critically evaluate the existing literature in light of this high-reliability computational challenge. 
Our review opens with a description of human shoulder anatomy and basic shoulder movements (see Section 2). This description is followed by a section on the challenges involved in shoulder kinematics (see Section 3 ). This is followed by the review search strategy, outline, classification and summary (see Section 5). This section is supplemented by a discussion in Section 6. Finally, we present possible research directions that can meet the high-reliability computational challenge (see Section 7).

\section{Functional anatomy and movements}

A functional shoulder is a pre-requisite for good upper arm functioning, as it places, operates and controls the forearm [40]. Without the active and significant contribution of the human shoulder, many daily living activities like hair combing and reaching the back cannot be performed successfully. Importantly, the musculoskeletal system provides the basis for constraining and allowing movement. This ability to generate movement is dependent on the structural morphology, which is studied under the realm of functional anatomy. Understanding the functional anatomy provides insight into the working aspects of any complex joint. Note that the muscular system and the structure of the various joint capsules are outside the scope of this paper.

\subsection{Bones and joints}

Bones are primarily rigid structures that form the supportive base for the muscles to act on. The kinematic role of the bone is approximated by straight-line distances between end-points known as links [31]. A detailed illustration of the shoulder articulation from the anterior and posterior views with labelled bony landmarks is shown in Figs. 1 and 2. The shoulder kinematic chain starts from the sternum, the chest bone that constitutes the midline of the anterior thorax. The sternum is followed by the S-shaped collar bone, known as the clavicle. The mechanical action of the clavicle is like that of a crankshaft $[5,31,41]$.

The third bone that forms the shoulder girdle is the flat posteriorly located bone known as the scapula. The positioning of the scapula in turn depends on the hand usage and loading [40]. The glenoid cavity of the scapula acts as
Fig. 1 Anterior view of right shoulder with the International Society of Biomechanics (ISB)-recommended bony landmarks: 1 incisura jugularis (IJ), 2 processus xiphoideus (PX), 3 sternoclavicular joint (SC), 4 acromioclavicular joint (AC), 5 processus coracoideus (PC), 6 glenohumeral joint (GH), 7 medial epicondyle (EM), 8 lateral epicondyle (EL), 9 angulus acromialis (AA), 10 angulus inferior (AI) (image courtesy: Visible Body Skeleton premium)

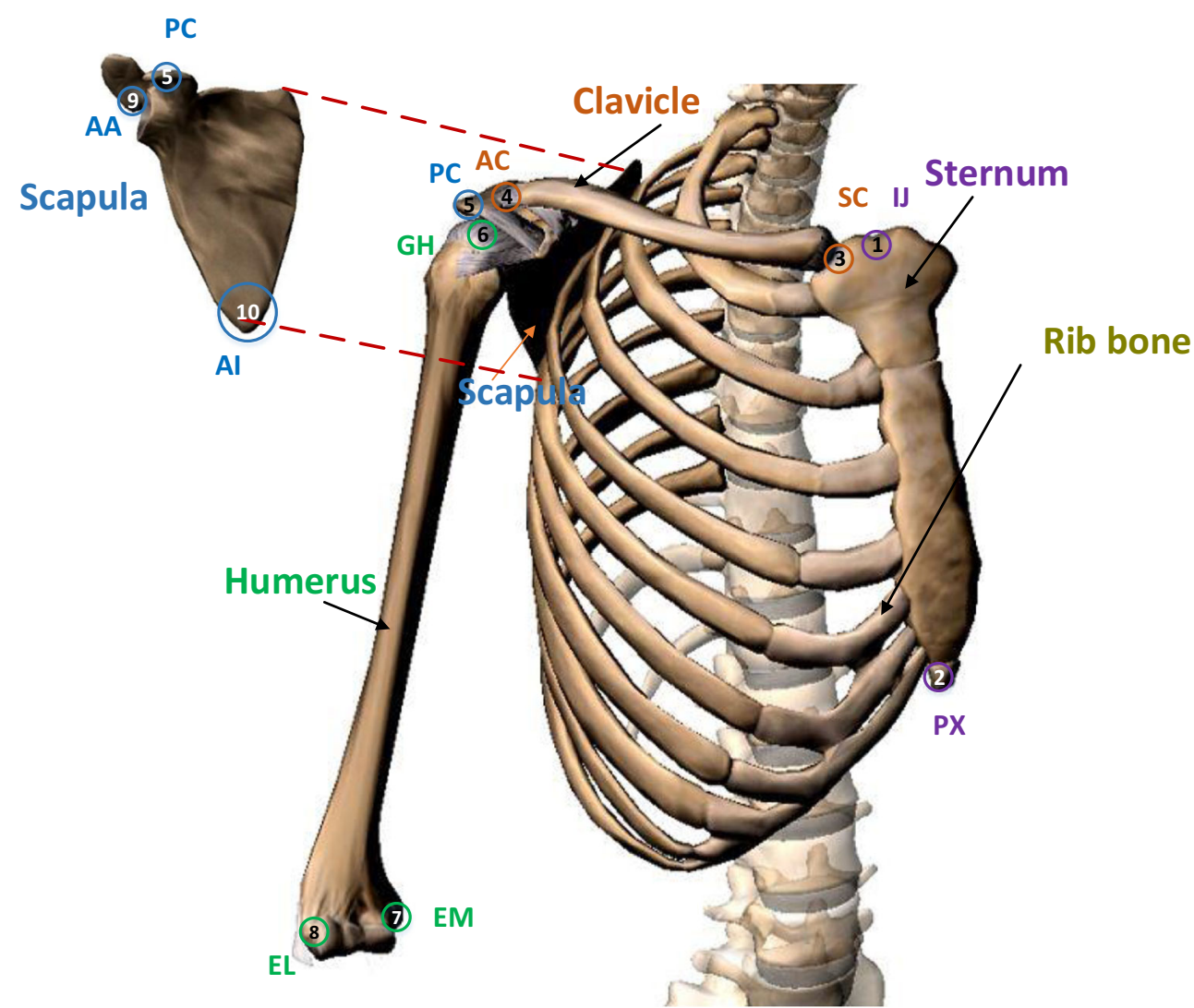


Fig. 2 Posterior view of the right shoulder with International Society of Biomechanics (ISB)recommended bony landmarks: 6 glenohumeral joint $(\mathrm{GH}), 11$ processus spinous 7 th cervical vertebra $(\mathrm{C} 7), 12$ processus spinous 8th thoracic vertebra (T8), 13 trigonum spinae scapulae (TS) (image courtesy: Visible Body Skeleton premium)

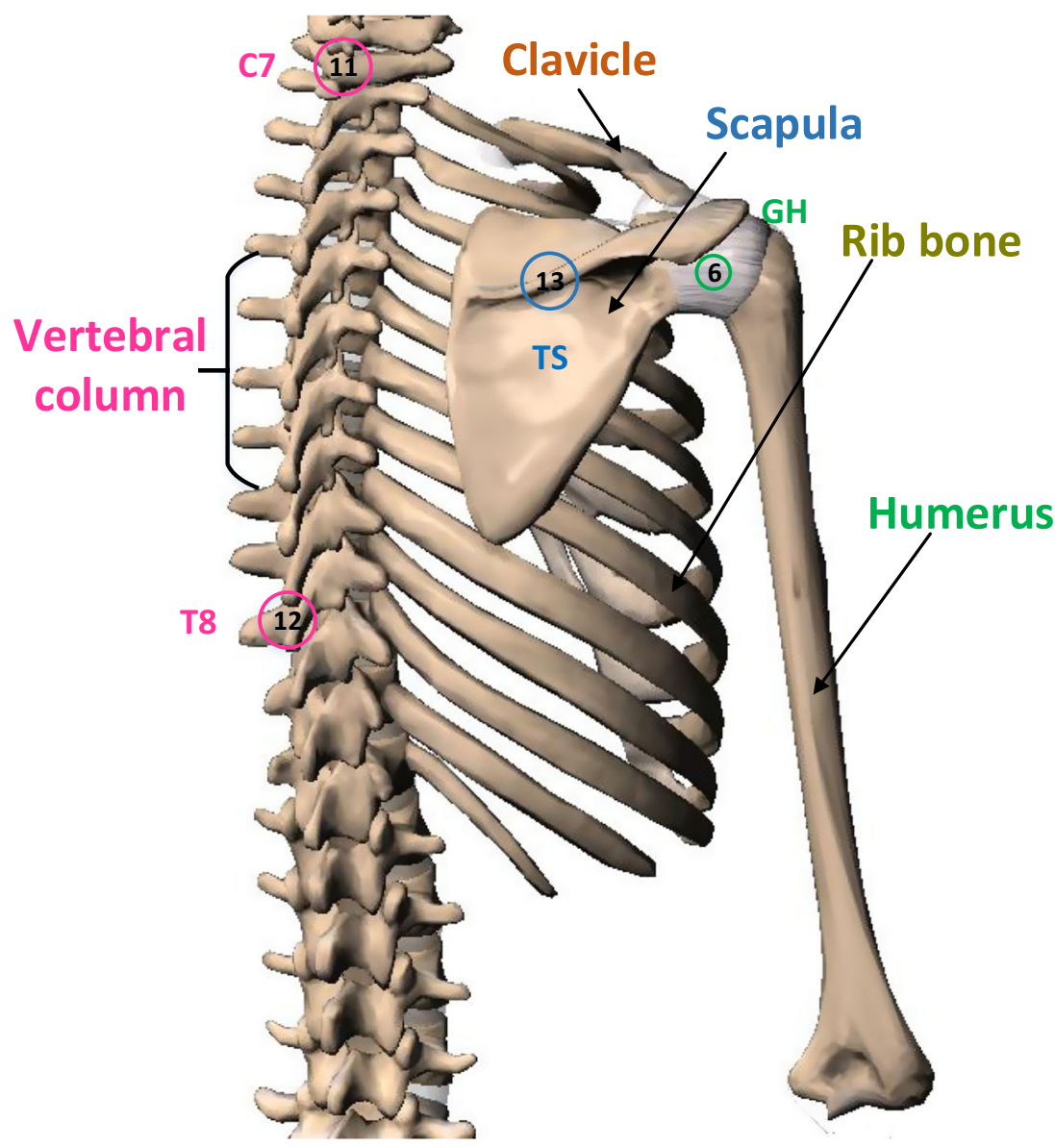

\subsection{Basic shoulder movements}

the site of attachment for the upper arm bone called the humerus. This attachment to the glenoid is mainly achieved through the spherical head of the humerus.

The joints are the meeting surfaces of the bones. There are three synovial joints in the shoulder. The interface between the sternum and the proximal end of the clavicle forms the sternoclavicular (SC) joint. The distal end of the clavicle connects with the acromion process of the scapula, forming the acromioclavicular (AC) joint. Furthermore, the humeral head articulates with the glenoid cavity of the scapula, forming the glenohumeral (GH) joint. Additionally, the concave anterior surface of the scapula slides over the convex surface of the thoracic cavity by sandwiching a group of soft tissues, forming the scapulothoracic (ST) joint. The ST is a functional joint that accounts for onethird of the shoulder ROM [42]. This fictitious joint is often modelled as a fixed [43] or dynamic contact [10, 44, 45]. Functionally, the shoulder girdle can be approximated by a non-existing humerothoracic (HT) joint, which is commonly found in activities of daily living (ADL) studies.
Although the joints of the shoulder articulation are capable of individual motions, their actions are not entirely sequential. Instead, they are simultaneous and well coordinated, resulting in the phenomenon of shoulder rhythm [42]. Importantly, the $\mathrm{GH}$ joint has the largest ROM among the shoulder joints due to its low bony congruency and capsular laxity [46]. This peculiarity of the shoulder articulation results in a diverse array of movements. Unfortunately, this diversity has resulted in confusion regarding the most suitable nomenclature for these movements. Therefore, we follow [47] as closely as possible.

An illustration of different basic shoulder movements is presented in Fig. 3. The shoulder movements in the sagittal plane are called flexion and extension. During flexion, the relative humeral angle between the rest position and the fully flexed position varies in the range $0^{\circ}-180^{\circ}$. The reversal of this motion results in the extension phase. If this 


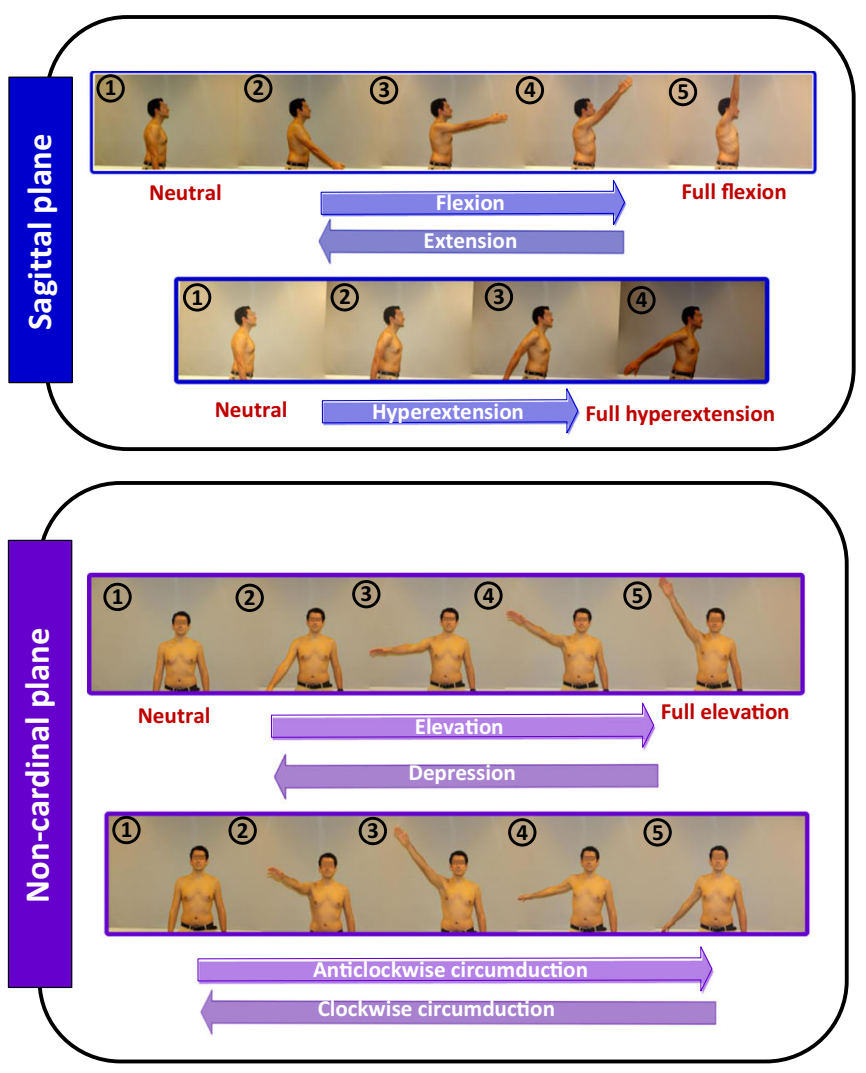

Fig. 3 Illustration of various basic shoulder movements

reversal proceeds posteriorly beyond the neutral position of the humerus, it results in hyperextension.

In the coronal plane, movement away from the mid-line of the body is called abduction. Similarly, the reverse motion from a fully abducted position to the mid-line is known as adduction. The movements in the transverse plane are internal rotation and external rotation, which constitute the internal or external axial rotation of the humerus. Additionally, the movement of the humerus about the vertical axis results in horizontal abduction, horizontal adduction and crossabduction, which are unique to the shoulder articulation.

Furthermore, there are movements that are not confined to any cardinal plane (see Fig. 3), namely, the conical movement of the humerus known as circumduction and the generalised raising and lowering of the humerus called elevation and depression.

\section{Challenges in investigating human shoulder kinematics}

There are several challenges in analysing shoulder movement, and they are related to anatomy, function, mathemat-

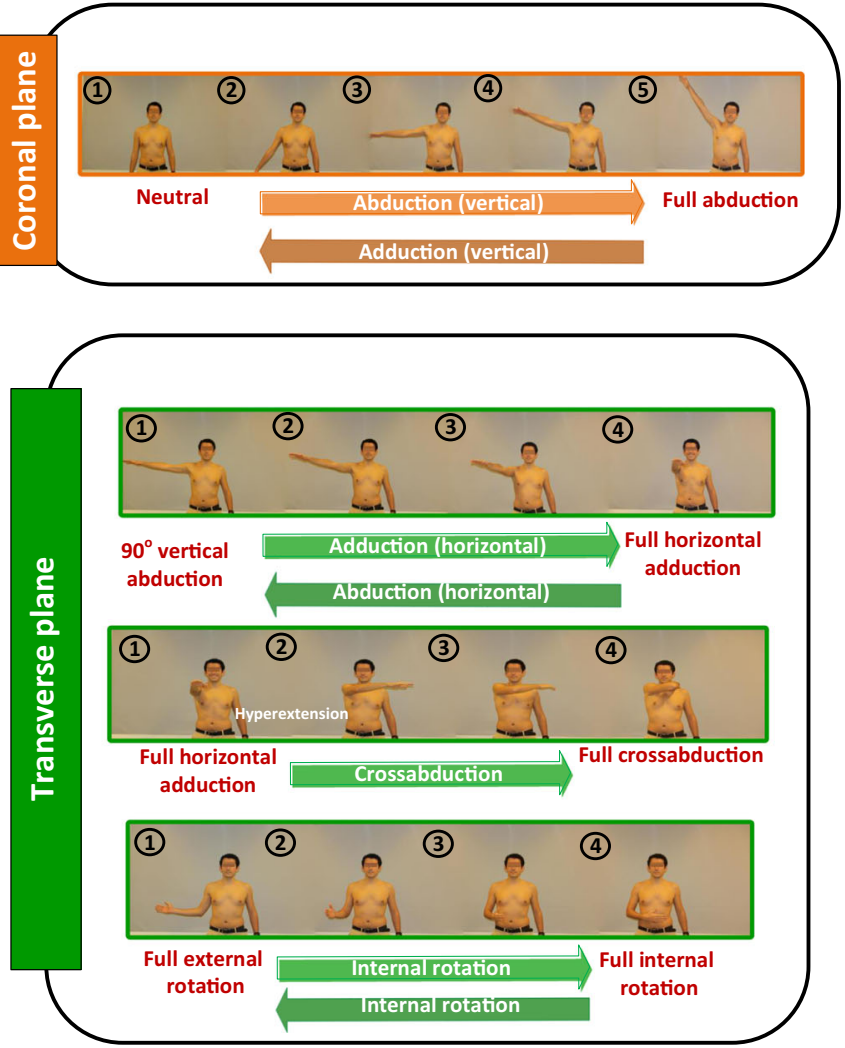

ical description, measurement difficulties or a combination of factors:

- Complexity: Human movement is a hierarchical phenomenon wherein the behaviour of the parts does not completely explain the behaviour of the whole, and vice versa [37]. Consequently, single-joint behaviour cannot completely account for multi-joint behaviour [39]. Such a situation makes it difficult to reliably parametrise the upper limb kinematics [48]. The complex anatomy (see Section 2) forces many researchers to limit their analysis to planar motion tasks. It is well known that such kinematic simplifications cannot effectively capture the variety of movements $[48,49]$.

- Inconsistent clinical description: Joint angles defined across the cardinal planes form the basis of human movement analysis. Importantly, the validity of generalised kinematics of rigid bodies depends on the symmetrypreserving properties of the underlying kinematic transformations. Mainly, these symmetry-preserving relationships are mathematically formalised using the notion of the theory of groups [50]. Mathematically, the 
clinical description does not form a group, which poses mathematical and interpretation difficulties, resulting in controversies such as the Codman paradox [50]. In the shoulder, the actual motions deviate significantly from the clinical description of the cardinal plane motions [6, 46, 48, 51].

- Measurement limitations: The large axial rotation of the humerus results in significant soft tissue artefacts (STAs) [4, 48, 50, 52-59], which presents measurement limitations. Recently, a study based on intra-cortical pins successfully quantified the effects of STA on humeral kinematics [60]. Additionally, a study by Naaim et al. [61] compares various multibody optimisation models in STA compensation for different ST joint models. Although this approach is very efficient in minimising the STA, the performance of these group of techniques does depend on the underlying kinematic model [62].

- Over-constrained system: Although the individual shoulder bones can move, their motion is often coupled and constrained. This pattern of coupled movement between the shoulder bones is popularly known as shoulder rhythm [63-65]. The extent of this rhythm depends on several aspects, including the plane and arc of elevation, joint anatomy and loading conditions [5, 40].

- Movement variability: Variability is an important issue in the literature on human movement. It is a major bottleneck in standardising upper arm kinematics [3]. Moreover, as upper limb movements are discrete, it is challenging to compare the inter-subject and intrasubject kinematics [48]. Movement variability has different origins of two main types: inter-subject and intra-subject variability [37]. Importantly, inter-subject variability has drawn attention and has led to many standardisation initiatives in human shoulder kinematics. The work of the International Shoulder Group (ISG) has led to the well-known International Society of Biomechanics (ISB) coordinate system [66] and an advanced framework [67]. In contrast, such initiatives only partially address the intra-subject variability. Intra-subject variability in movement kinematics is known to emerge from four main factors: representational mismatch, non-standardised protocols, different data processing methods and the actual variability in movement.

\section{An overview of human shoulder kinematic representations}

This section presents a brief review of prominent kinematic representations used to parametrise shoulder movement. We begin with an overview of the relative kinematics problem and present the various mathematical representations used in the literature to address this problem.

Generalised relative kinematics problem As is evident from Section 2.2, the distal segment is always described relative to the proximal segment, which is known as the relative kinematics problem. Consider Fig. 4, a compact way to represent the relative kinematics between the moving body $B$ and reference body $A$ is given by the homogeneous transformation matrix $\mathbf{T}$,

$\left[\begin{array}{c}x^{A} \\ y^{A} \\ z^{A} \\ 1\end{array}\right]=\left[\begin{array}{c|c}\mathbf{R}_{\mathbf{3} \times \mathbf{3}} & \mathbf{t}_{\mathbf{3} \times \mathbf{1}} \\ \hline \mathbf{0}_{\mathbf{1} \times \mathbf{3}} & 1\end{array}\right]\left[\begin{array}{c}x^{B} \\ y^{B} \\ z^{B} \\ 1\end{array}\right]=\mathbf{T}\left[\begin{array}{c}x^{B} \\ y^{B} \\ z^{B} \\ 1\end{array}\right]$

Here, $\mathbf{R}$ and $\mathbf{t}$ represent the rotation and translation of frame $B$ with respect to frame $A$, respectively. In human movement, these frames can be defined using anatomical landmarks, mechanical points or axes, or their combination [68]. Note that the interpretation of kinematic data is sensitive to the choice of these frames of reference. In HRI, the robot is equipped with different motion sensors that act both as a measurement system and as a feedback loop. The kinematic representations presented in this section differ in how elements of $\mathbf{T}$ are computed [69]. We present below the prominent kinematic representations in shoulder kinematics below.

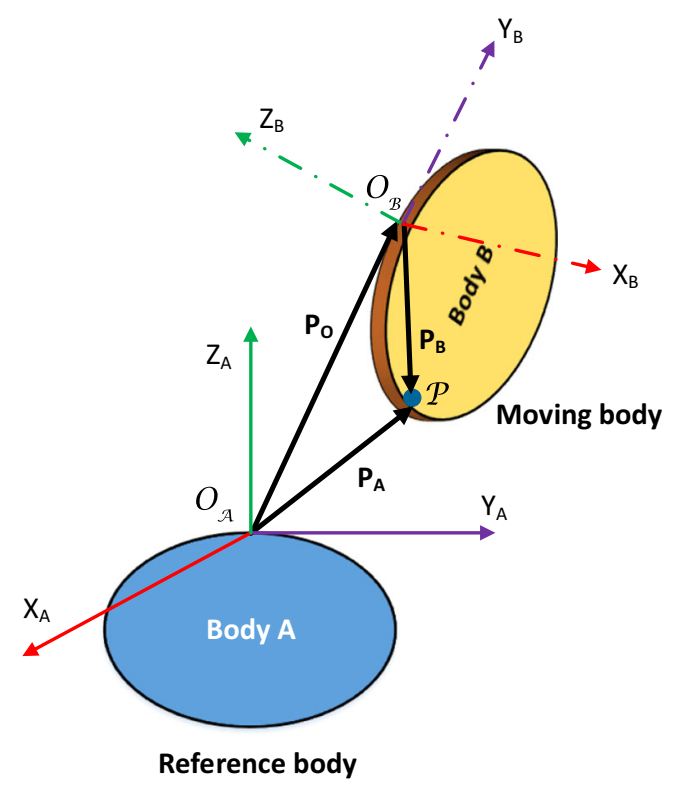

Fig. 4 Generalised relative kinematics 


\subsection{Euler/Cardan angles}

Due to the simplicity and intuitive nature of Euler angles, they are very popular in the shoulder kinematics literature. In Euler angles, the rotation matrix $\mathbf{R}$, defined in Eq. 1, is interpreted as a product of three sequential rotational transformations $\mathbf{R}_{\mathbf{i}}, \mathbf{R}_{\mathbf{j}}$, and $\mathbf{R}_{\mathbf{k}}$ about the axes $i, j$, and $k$.

$\mathbf{R}_{(\mathbf{i}, \mathbf{j}, \mathbf{k})}=\mathbf{R}_{\mathbf{i}}\left(\theta_{\mathbf{1}}\right) \mathbf{R}_{\mathbf{j}}\left(\theta_{\mathbf{2}}\right) \mathbf{R}_{\mathbf{k}}\left(\theta_{\mathbf{3}}\right)$

Here, $i, j, k \in\{X, Y, Z\}$, provided $i \neq j, j \neq k$, resulting in 12 different sequences of Euler/Cardan angles. When $i \neq k$, the resulting asymmetric Euler angles are called Cardan angles [68]. The ISB recommends a symmetric Euler sequence, YXY, for reporting HT kinematics [66].

Although Euler angles are popular due to their intuitive nature, they present limitations due to their numerical instabilities, temporal nature and interaction issues [70]. Numerical instabilities or gimbal lock occurs at $\theta_{2}= \pm \frac{\pi}{2}$ for Cardan angles and at $\theta_{2}=0, \pm \pi$ for Euler angles.

\subsection{Joint coordinate system}

Inspired by the clinical movement definition, Grood and Suntay proposed the joint coordinate system in [71]. The joint coordinate system (JCS) includes six parameters, three each for rotation and translation. Importantly, the JCS description is a part of the ISB recommendation for several shoulder joints [66]. Figure 5 shows the relative kinematics problem in terms of JCS definition as given in [71].

It is known that the JCS is equivalent to the corresponding Cardan sequence [72] and can be extended to other parameterisations [71]. Similar to Euler angles, numerical singularities also occur in the JCS, at $\beta=0$ and at $\beta=0, S_{2}=0$ [71]. Importantly, the JCS is sensitive to the choice of $\mathbf{e}_{\mathbf{1}}$ and $\mathbf{e}_{\mathbf{3}}$; an unsuitable choice can result in substantial kinematic cross-talk. The claim that JCS is "sequence-independent" in [71] is incorrect, as the specific choice of the embedded axes itself imposes a sequence effect [72].

\subsection{Denavit-Hartenberg parameters}

In robotics, the relative kinematics problem is often solved using the Denavit-Hartenberg (D-H) convention. In D-H parameters, the homogeneous transformation $\mathbf{T}$ in Eq. 1 is represented by a set of four parameters. These parameters for an $i$ th joint are the link length $\left(a_{i}\right)$, the link twist $\left(\alpha_{i}\right)$, the link offset $\left(d_{i}\right)$ and the joint angle $\left(\theta_{i}\right)$. These parameters define the geometry of link $i$ with respect to link $i-1$ about a joint $i$, as shown in Fig. 6. The joints that connect these links can be of either the rotary or prismatic type. In that case, $\theta_{i}$ parameterises the rotary joint, and $d_{i}$ parameterises the prismatic joint. Because the D-H parameter definition

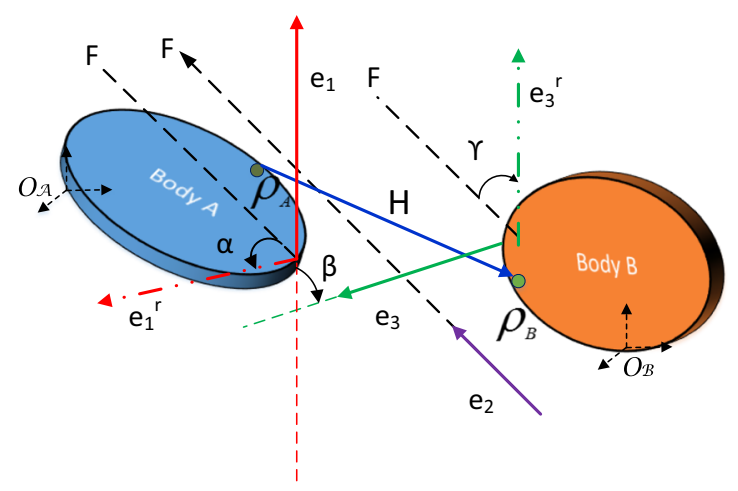

(a) JCS orientation parameters

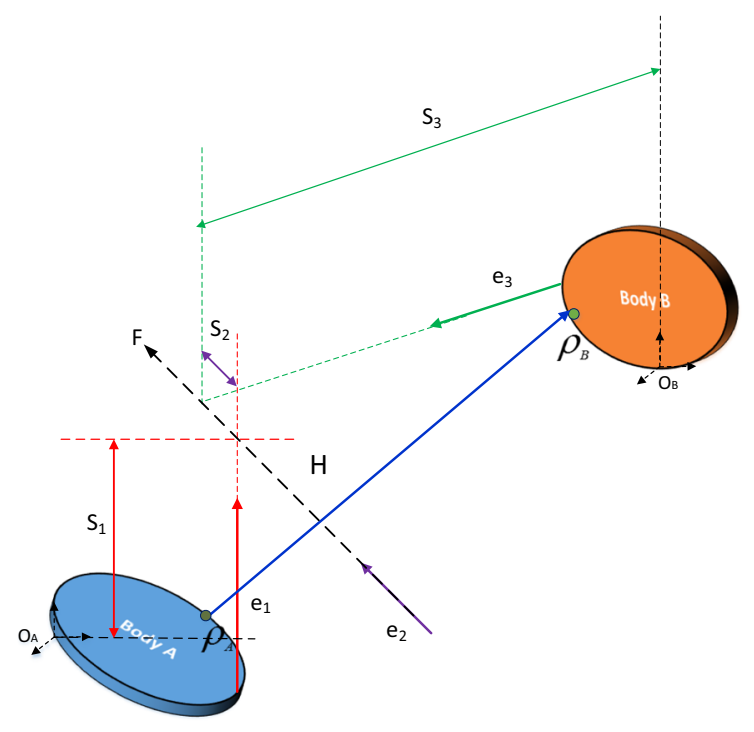

(b) JCS clinical translation parameters

Fig. 5 Concept of JCS and 3D motion description adapted from [71] 


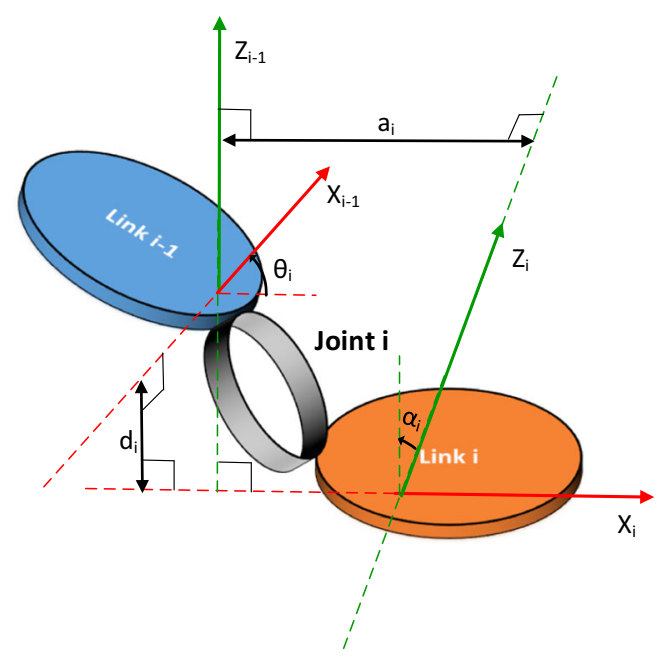

Fig. 6 Denavit-Hartenberg parameters for joint $i$ connecting link $i$ and link $i-1$

is not unique, we follow the popular convention presented in [73]. In this case, the homogeneous transformation is given by

$\mathbf{T}=\left[\begin{array}{cccc}\cos \left(\theta_{i}\right) & -\sin \left(\theta_{i}\right) \cos \left(\alpha_{i}\right) & \sin \left(\theta_{i}\right) \sin \left(\alpha_{i}\right) & a_{i} \cos \left(\theta_{i}\right) \\ \sin \left(\theta_{i}\right) & \cos \left(\theta_{i}\right) \cos \left(\alpha_{i}\right) & -\cos \left(\theta_{i}\right) \sin \left(\alpha_{i}\right) & a_{i} \sin \left(\theta_{i}\right) \\ 0 & \sin \left(\alpha_{i}\right) & \cos \left(\alpha_{i}\right) & d_{i} \\ 0 & 0 & 0 & 1\end{array}\right]$

In shoulder kinematics, the GH joint is often parameterised as a pure spherical joint. This effect is obtained by choosing three intersecting revolution DOF with a common origin. The D-H parameters are also equivalent to Euler angles and the JCS. Hence, numerical singularities occur. Note that the D-H parameters cannot be used in closedloop kinematic chains as the parameter definitions become inconsistent [74].

\subsection{Other shoulder representations}

Other representations are used in literature, though somewhat less prominently. The shoulder is often modelled as a combination of serial and parallel chains, which is known as a multibody or hybrid mechanism [62, 75-77]. The globe representation describes functionally important shoulder kinematics that are not restricted to the cardinal planes $[78,79]$. Engin [80] used the finite helical axis (FHA) to compute the HT centrode during a humeral elevation task. Sweeping the bony links over the extreme range of motion of a joint results in an excursion cone, called a joint sinus cone [31]. An application of joint sinus cones in virtual human modelling is presented in [81].

\section{Review: search strategy, outline, classification and summary}

We begin this section by presenting the search strategy and outline of the review, followed by the classification system used to organise the relevant literature. Subsequently, we summarise the key findings of this review.

\subsection{Search strategy}

A systematic search based on the ISI Web of Science database was conducted on the 31 August 2017. The search keywords were "Human shoulder kinematics", which yielded 1223 hits. Based on our review context, a four-stage detailed filtering procedure was used to narrow down the list of articles. Stages 1-3 of this filtering were based on the title and the details of the article abstract, which yielded a tentative list of 207 articles. The details of this search and inclusion strategy are presented in Fig. 7.

Recall that in the context of a functional shoulder, it is understood that clinical questions related to joint pathology, dysfunction, pain and stability are not relevant. Additionally, a few articles used healthy subjects as a control in their respective study. Using the above exclusion criteria, in Stage 4, a total of 56 articles were excluded, as they were connected to cerebral palsy (3), stroke (12), exoskeleton design (4), development disorder (6), sports (6), mechanism design (6), clinical review (1), motion classification (1), measurement (2), clinical questions (4), healthy subjects used as control (2), human-robot interaction (3), ergonomics (4) and animation (1). Additionally, one article was found to be indexed twice by the search engine and was discounted, resulting in a final list of 151 articles for review tabulation.

\subsection{Review table outline}

The list of relevant papers identified in Section 5.1 is summarised in Table 1 in the Appendix. Furthermore, individual papers are arranged in rows with the columns divided into six items, namely, citation, the kinematic representation used in the study, the purpose of the study, the details of the subjects used in the study, the type of measurement instrumentation used and the activities studied.

Because the majority of studies use Euler angles, they have been indicated by the relevant sequence only. The 
joints of interest in the respective studies have been indicated by appropriate abbreviations presented in Section 2.1.

Because the statistical validity of any study depends on the number of subjects involved, we decided to highlight the subjects used in the reviewed articles by indicating the total number of subjects in the study, followed by their details: male $(\mathrm{M})$, female $(\mathrm{F})$, child $(\mathrm{C})$ and their respective age distributions.

The method of human motion tracking used is crucial. Therefore, we have also tabulated the variety of measurement techniques used in the reviewed articles. Additionally, the different movements in the study have been summarised. Let us proceed to examine the classification system used to organise the literature.

\subsection{Classification scheme for reviewed papers}

From Section 4, it is clear that there is a large diversity among the kinematic representations used in the shoulder kinematics literature. Although it is challenging to classify the available literature, we have proposed a three-point classification strategy, which is discussed below.

Fig. 7 Search strategy

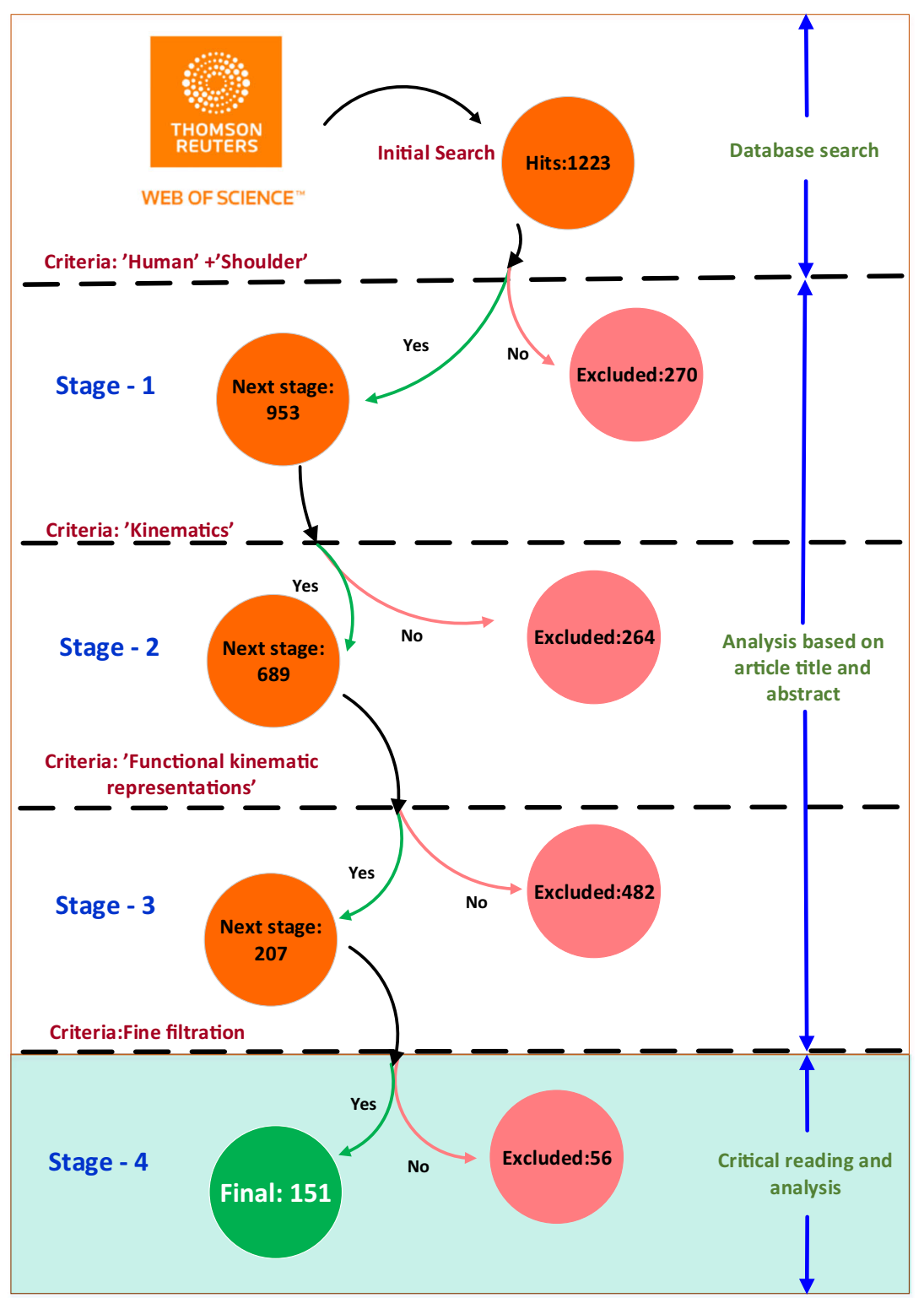




\subsubsection{Realistic or humanoid representation}

What is the real nature of shoulder motion? The answer to this simple question is not straightforward, because the definition of reality is both context- and purpose-specific in nature. A recent survey and experimental study provides a detailed summary on the use of multibody methods in upper limb kinematics [62, 82]. As discussed in Section 2, the functional shoulder motion consists of simultaneous rotations and translations. Because HRI is situated in real world, it is important that the models used in cHRI are realistic [22]. Therefore, in the context of high-reliability HRI, we classify the studies that represent the shoulder joint as a ball-and-socket joint as a humanoid. In contrast, the studies that treat the shoulder otherwise are classified as realistic. Additionally, following the recommendation by El-Habachi et al. [83], the studies that treat the shoulder as a closed-loop kinematic chain are considered realistic. Because the majority of the reviewed papers use a humanoid approach in parameterising human shoulder kinematics, we indicate realistic studies by the footnote marker $(*)$.

\subsubsection{Forward or inverse kinematics}

In shoulder kinematics, finding the humeral position given the individual joint configurations poses the forward problem. Note that the forward problem has guaranteed uniqueness [8, 84]. Forward studies commonly extend our understanding of individual joint contributions and our knowledge of the human arm-reachable workspace. In contrast, finding the joint variables from the kinematic measurements poses the inverse problem. Note that this challenging problem has no unique solution [8]. In both cases, the kinematic inference is based on the representation of choice. Note that because there are only a handful of forward studies in shoulder kinematics, we denote them using the footnote label $(\dagger)$.

\subsubsection{Biological context}

Traditionally, the anatomical understanding has emerged from studies based on human cadavers, which are known as in vitro studies. However, it is well known that in vitro studies do not replicate the properties of any living shoulder [41, 59, 85, 86]. Studies based on living humans are called in vivo research [86]. Increased computational power has enabled numerical and simulation studies of the musculoskeletal system, which are known as in silico studies [86]. They play an important role in investigations that would be otherwise impossible to measure or quantify or would require an invasive approach [49]. An example of an in silico study in the context of musculoskeletal surgery is given in [87]. In silico models will play a significant role in future research because cadaveric studies are expensive and pose ethical challenges [50].

Although the classification system is quite straightforward, in reality, different studies have used all the above three combinations to varying degrees. The majority of the reviewed papers fall under the purely in vivo category. Therefore, we denote the in vitro studies by (!), the in silico studies by (II), the combination of in vivo and in vitro studies by $(+)$, the combination of in vivo and in silico studies by $(\%)$ and not an in vivo study by (\#).

\subsection{Review summary}

In Table 1 in the Appendix, the entries have been grossly grouped according to the kinematic representations used: Euler angles, D-H parameters, joint coordinate system and other. Out of the 151 reviewed studies, Euler angles were used by 37 studies, whereas JCS was used by 35 studies. The popularity of these representations might be due to the intuitive nature of both of these representations and their closeness to the clinical definition. Figure 8 presents the results of the literature classification of our survey. Note that the majority of the reviewed papers are in the humanoid, inverse kinematics and in vivo categories.

We could also see that the purpose of the various studies is diverse. The most frequent ones are $\mathrm{GH}$ kinematics [34, 50, 52, 55-57, 59, 85, 88-98], scapular kinematics [55, 99-119] and shoulder rhythm [58, 65, 116, 120-125]. Several studies in shoulder kinematics have been interested in analysing the effects of various factors on kinematics, including age [112, 122, 126, 127], load [58], dominance $[57,128,129]$ and gravity [130].

The frequency of the basic shoulder movements in the reviewed literature is presented in Fig. 9. This histogram shows that shoulder abduction and flexion are frequently evaluated in kinematic analysis. They are followed by abduction in the scapular plane, which is seldom used in daily life. The preference for the abduction movement might be due to the ease of measurement and the almost ball and socket behaviour of the GH joint during the initial phases of abduction. However, internal/external rotation and elevation were used less frequently. The reason might be connected to the presence of STA, which might pose initial measurement challenges. In contrast, the abduction movement generates the least STA. Additionally, several studies [4, 33, 38, 126, 131-141] took an interest in analysing ADL. 
Fig. 8 The histogram shows the number of reviewed articles classified according to the categories presented in Section 5.3. The three different colours respectively represent the three literature classification categories

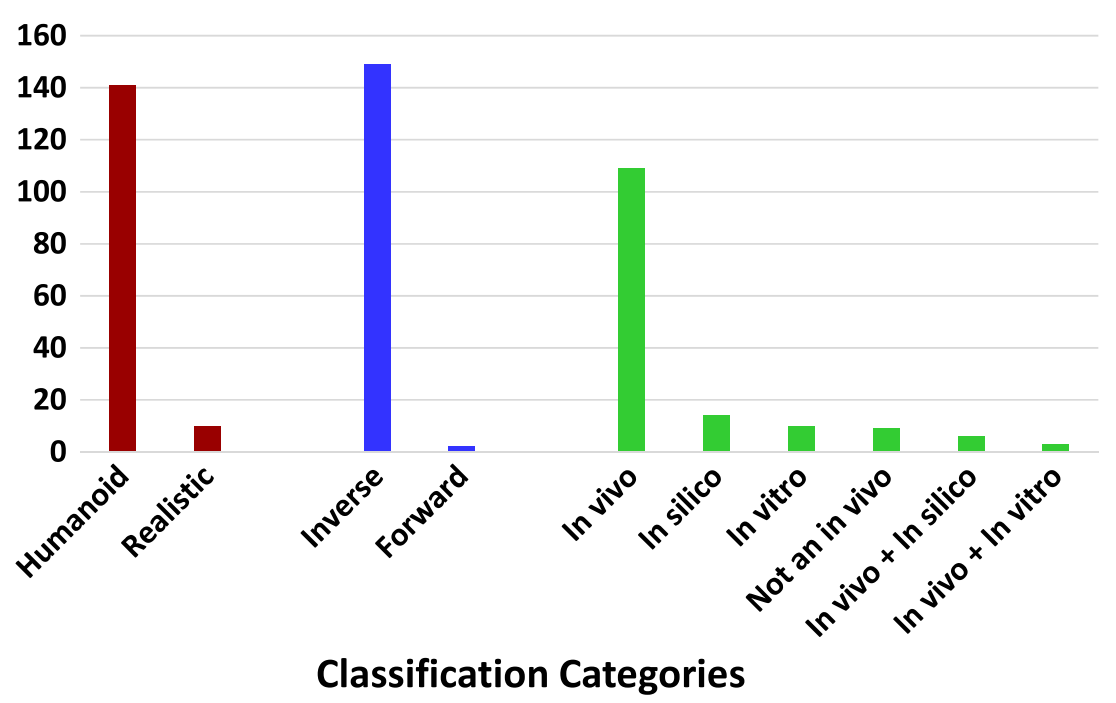

\section{Discussion}

Although the ISB recommends the Euler YXY sequence for reporting HT kinematics, there is a lack of consensus on the best rotation sequence [142]. In 3D-ROM analysis, it is a common practice to extrapolate the planar ROM, but it is now known that such analysis leads to $60 \%$ nonphysiological poses [46].

Because the GH joint has the largest ROM in the shoulder, it is a common practice to approximate the shoulder kinematics to that of the GH joint. Therefore, a common assumption prevails that the GH joint is equivalent to a ball and socket joint, which we will challenge below.

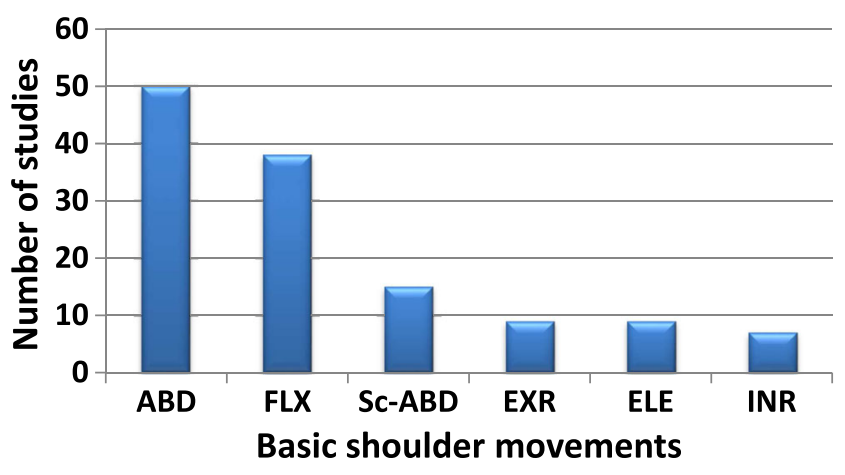

Fig. 9 A summary of major shoulder movements in the literature. Note that only the movements that occur with a frequency greater than five are considered here. The notations are as follows: ABDabduction, FLX - flexion, Sc-ABD — adduction in the scapular plane, EXR - external rotation, ELE-elevation and INR - internal rotation

\subsection{Ball and socket assumption}

Fundamentally, the ball and socket assumption neglects the role of joint structures such as ligaments [34, 94], translations [54], joint asymmetries [95] and the role of the girdle $[14,50,143]$. This assumption only holds for a small ROM and deviates significantly during a large ROM [144]. Therefore, it can be argued that this approach is an inappropriate use of reductionism. Hence, the validity of this assumption in high-reliability applications must be reconsidered.

Thus, it can be argued that the GH joint alone cannot completely capture the function of the shoulder articulation. Moreover, mathematical simulations aimed at comparing the pure GH and the whole girdle workspace have shown significant kinematic differences [77]. Importantly, as we have emphasised before, even small ROM contributions from joints other than the GH are important and significantly affect the end goal of an activity [139]. However, this simplification remains popular due to the ease of clinical interpretation [50].

\subsection{Kaltenborn's convex-concave rule}

Approximating the shoulder articulation by lower kinematic pairs (see Section 4) is based on the assumption that the articulation follows the convex-concave principle [2]. This principle describes the relation between a joint's congruency and its kinematics [47]. The principle is stated as: "A concave joint surface will move on a fixed convex surface in the same direction the body segment is moving. On the other 
hand, a convex joint surface will move on a fixed concave surface in the opposite direction as the moving body segment [47]." Importantly, several experimental studies have shown that the convex-concave rule is violated by the shoulder even for simple movements [145, 146]. Moreover, the validity of this reductionism in turn depends on the joint curvature [147]. If the shoulder articulation does not follow this rule, the error we commit in assuming a lower kinematic pair is significant. Therefore, it is important to reconsider this incorrect usage of reductionism in the context of highreliability applications.

\subsection{A note on common kinematic errors}

1. The spherical coordinate system presented in [148] uses a combination of rotations about the local and global axes that is not recommended [149]. Although the representation can be physically intuitive, note that spatial rotations are path-dependent even if their initial and final positions are the same [38]. Therefore, it is mathematically incorrect to claim "sequence independence". Such a situation can be avoided by precisely and explicitly describing the steps, rotation vectors, axis orientations, reference frames and order of rotation [149].

2. Another common erroneous usage of rotation angles is in the computation of ROM, when researchers treat them as vectors. Importantly, this approach can result in the misinterpretation of phenomenon [150]. Instead, it is recommended to use the difference of rotation matrices to extract the ROM [150].

\section{Moving towards high-reliability human-centric kinematic models}

Now, we ask whether the existing shoulder kinematic representations are suitable for high-reliability HRI. Based on our review, it is clear that humanoid representations (see Section 5.3.1) are the most commonly preferred ones in shoulder kinematics. Undoubtedly, this approach represents a highly simplified situation. Such simplifications make error due to representational mismatch unavoidable. Moreover, the non-linear and time-varying nature of kinematics exacerbates this situation, thereby undermining the very purpose of these representations. This computational challenge is even more daunting in the case of the humancentric models that form the basis of HRI [12, 48]. For successful robot-assisted rehabilitation, the robot needs to somehow incorporate the knowledge of the patient's health that emerges from functional understanding.
Importantly, existing clinical scales in rehabilitation have been criticized to be low in validity, reliability and sensitivity [28]. Moreover, for such an analysis, it is time consuming and expensive to collect data. Alternatively, a robot-based or sensor-based solution can provide highquality data; thereby, many of the above limitations can be overcome [28]. If properly designed, robot-based rehabilitative solutions can simplify the patient's assessment [28]. With highly reliable rehabilitation technology, even the group size for the randomised control trials (RCTs) can be reduced [28, 151]. Eventually, we will be able to minimise the high costs involved in running RCTs [152]. Moreover, highly reliable measurements will enhance the confidence in the interpretation of clinically relevant treatment effects [153]. Therefore, improving the measurement reliability will have a significant impact on the future of both rehabilitation research and practice $[151,152]$.

\subsection{Meeting the high-reliability computational challenge}

As we have mentioned before, meeting this challenge remains an open research question. Therefore, for possible answers, we might have to look beyond current approaches in biomechanics, robotics and human motor control [48]. Therefore, we suggest possible ways to meet this computational challenge.

\subsubsection{Embracing redundancy}

Biologically, redundancy is advantageous and highly desirable [135]. However, minimalist parameterisations such as the Euler angles are widely preferred, as is evident from our review (see Table 1 in the Appendix). Mainly, these representations cannot effectively capture this inherent redundancy in upper limb kinematics [34, 135]. Mathematically, minimal representations using three parameters are prone to numerical singularities [149], which are undesirable in high-reliability applications.

One of the strongest criticisms against minimalism is that the computational power of the human brain is immense. Therefore, controlling multiple DOF should not pose any problem to the human brain [154]. Although simplicity and lower levels of abstraction are highly desirable traits in a model, it can be argued that such an approach provides only limited understanding in applications such as robot-assisted rehabilitation [155]. Non-minimal representations, however, need to be backed by highly reliable measurements [34]. Moreover, complexity in mathematical representation leads to an increased level of abstraction, resulting in 
interpretation difficulties [34]. These points are important limitations of redundant approaches. However, the issue of redundancy holds the key to the high-reliability computational challenge. Therefore, we believe that new kinematic representations might present a possible answer to this challenge.

\subsubsection{Incorporating the translations well}

As can be seen in Section 6.1, the shoulder function is mathematically approximated by a ball and socket joint. In fact, it is a challenge to encode the translations using the clinical movement definition [34, 50], which motivates the widespread use of this approximation. Through a slight change in the mathematical perspective, however, it is possible to handle the simultaneous rotation and translation with ease.

Mathematically, the order in which the homogeneous transformation matrix is decomposed into rotation and translation has important implications, as this decomposition is not commutative (see Eq. 1). Generally, the homogeneous transformation is decomposed following the displacement first and rotation second rule. This rule results in the passive kinematic interpretation of the movement [156]. In contrast, reversing this order of interpretation results in an active interpretation [156]. Importantly, active interpretations embed translations effortlessly without the need of any explicit body-fixed frame. Although active representations are simpler, their clinical interpretation is still difficult. Because existing clinical interpretation is inherently passive. Currently, it is challenging to switch between active and passive kinematic representations [157].

\subsubsection{Emphasis on functional understanding}

Thus far, current approaches in shoulder kinematics fall under the umbrella of deterministic models, especially if they are hierarchical in nature. In hierarchical models, the mechanical quantities involved in the first level must completely determine the factors included in the next higher level [158]. Conversely, the performance of these models worsens in the presence of joint translations and irresolvable information on axial rotations $[159,160]$. On a similar note, a common criticism exists that the hierarchical approach does not contribute to functional understanding [161].

An alternative to this existing approach is the 6-DOF approach, which can potentially address many of the abovementioned shortcomings of the hierarchical models. The 6-DOF models can ensure kinematic decoupling, lower error propagation and better tracking of non-sagittal joint rotations [159]. However, the 6-DOF marker set is sensitive to noise [159]. Despite this shortcoming, the 6DOF models have the potential to be used in high-reliability HRI because such an approach would enhance functiona 1 understanding.

Movement kinematics forms the cornerstone of today's neuromuscular modelling. Therefore, kinematics will be crucial in addressing many open problems in neuromuscular modelling: development of universal biological joint, rigorous validation of developed models, and not limited to automating movement analysis [86]. From the perspective of robot-assisted rehabilitation, future cognitive models must be able to answer the "When to assist and what to assist?" question [21].

\section{Conclusions}

In conclusion, we have highlighted the importance of shoulder articulation in daily life, and we have systematically searched and compiled the existing literature on human shoulder functional kinematics. We have thereby successfully highlighted important gaps in our current knowledge with respect to the high-reliability computational requirement, in applications such as robot-assisted rehabilitation. The findings of our review were reframed in the light of this high-reliability computational challenge. It was found that current approaches in different disciplines cannot meet this challenge. Possibly, this challenge could be met by new kinematic representations that are redundant, active and that emphasise on functional understanding. Therefore, more efforts are needed in this direction. Only then can robot-assisted rehabilitation reach its full potential.

Acknowledgements The authors thank Sebe Stanley Mulumbawa for his help in rechecking the review table.

Funding information This work was funded by VINNOVA project AAL Call 6-AXO-SUIT (AAL 2013-6-042).

\section{Compliance with ethical standards}

Competing interests The authors declare that there are no competing interests.

Open Access This article is distributed under the terms of the Creative Commons Attribution 4.0 International License (http:// creativecommons.org/licenses/by/4.0/), which permits unrestricted use, distribution, and reproduction in any medium, provided you give appropriate credit to the original author(s) and the source, provide a link to the Creative Commons license, and indicate if changes were made. 


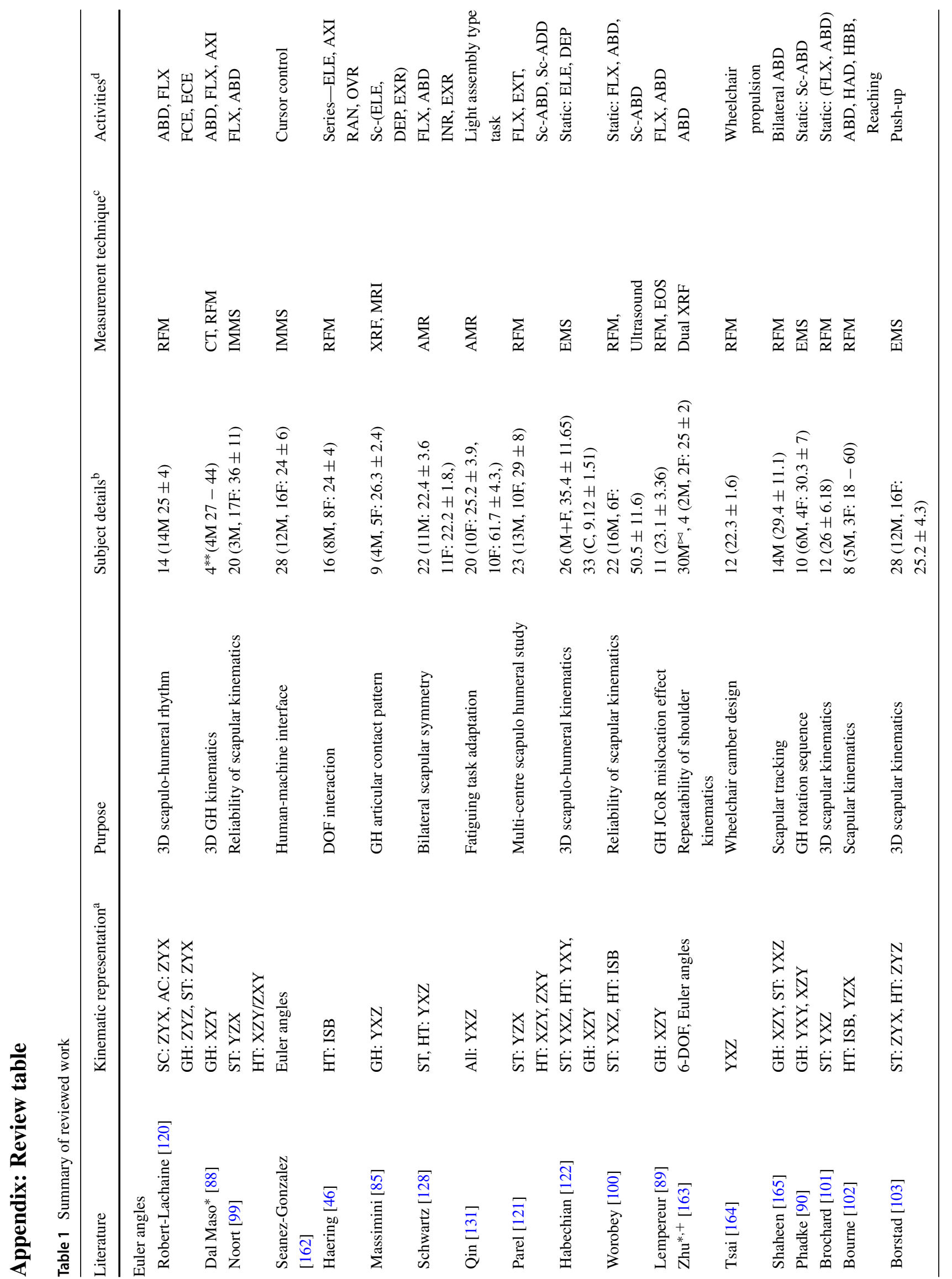




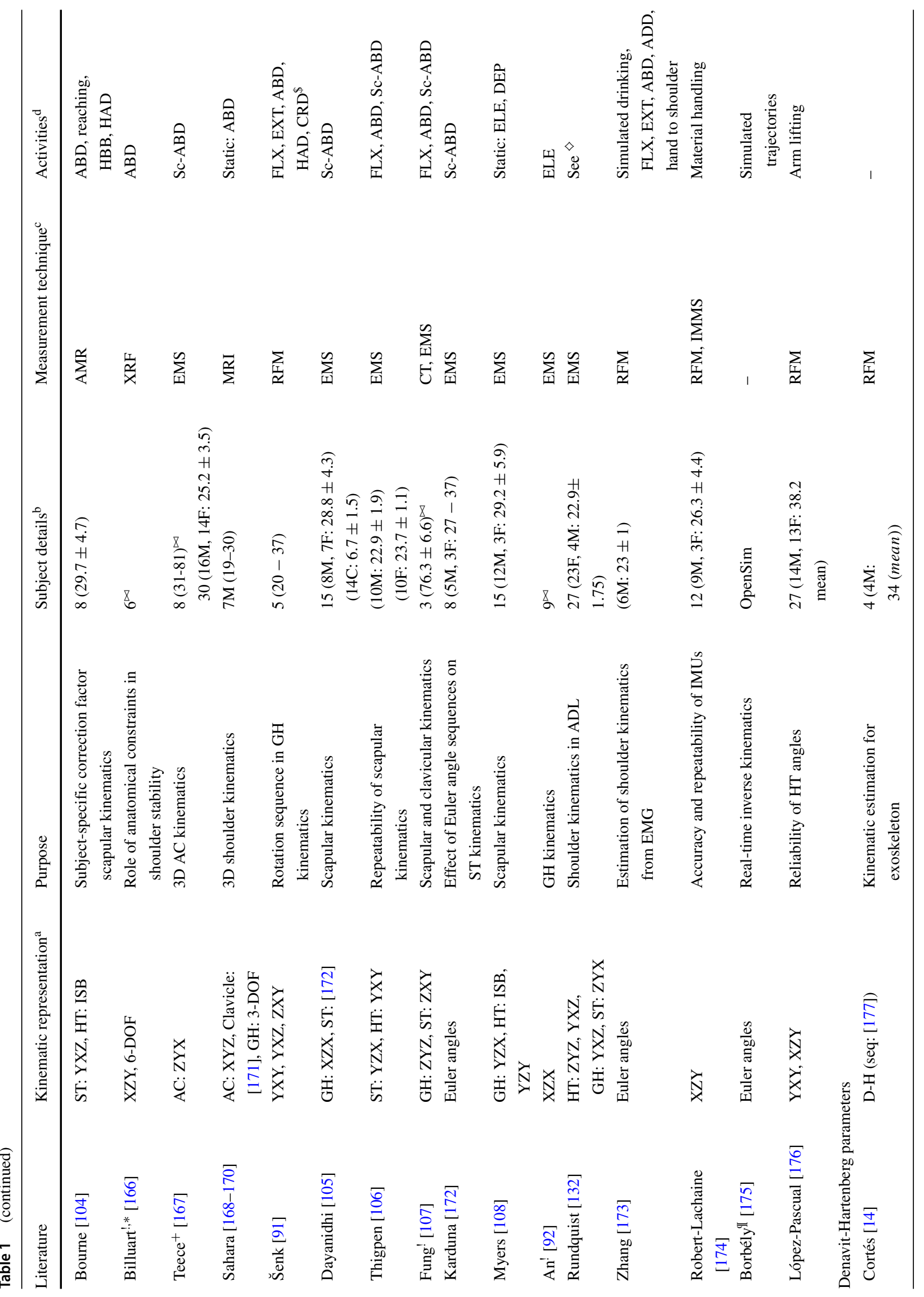




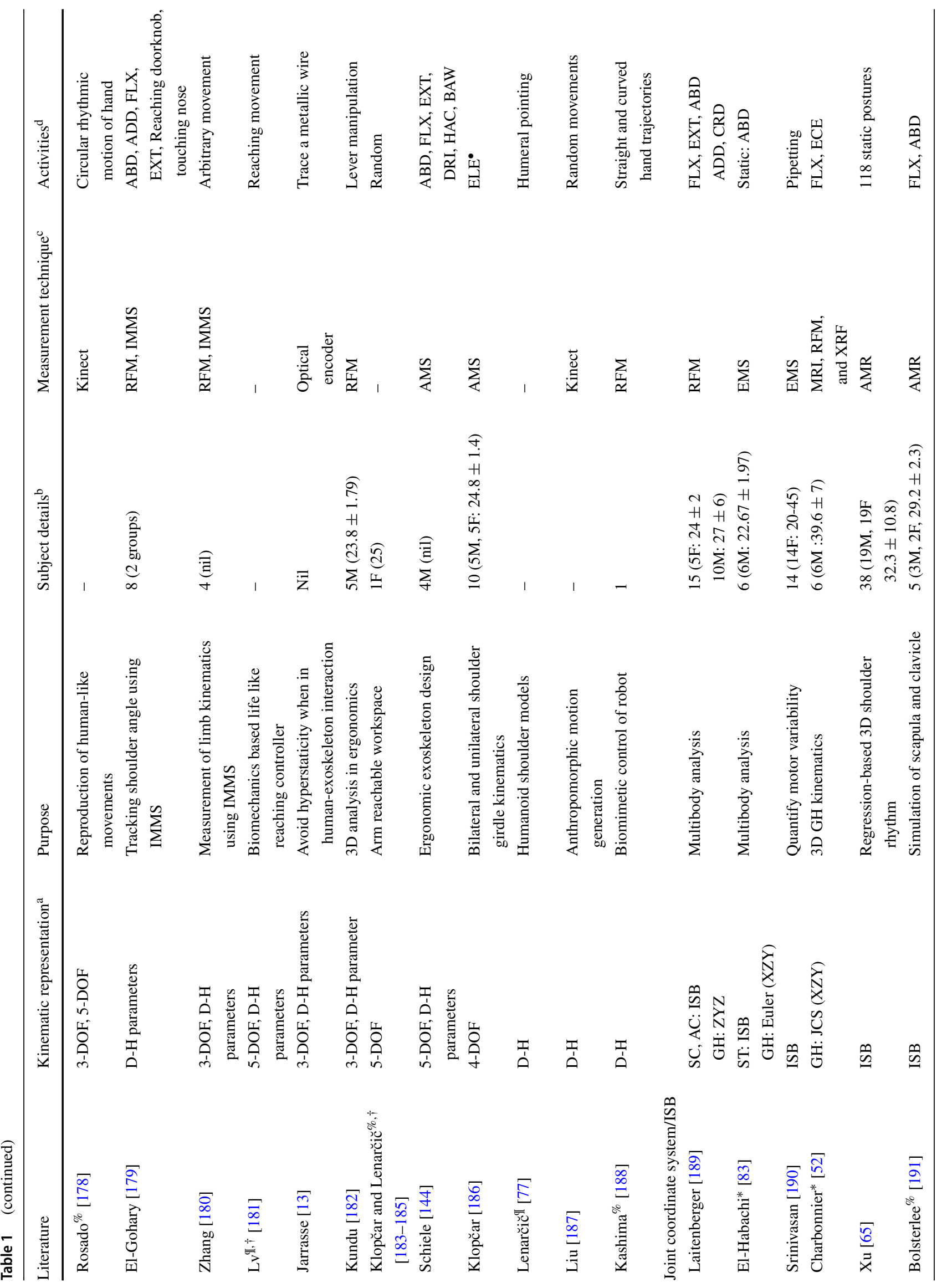




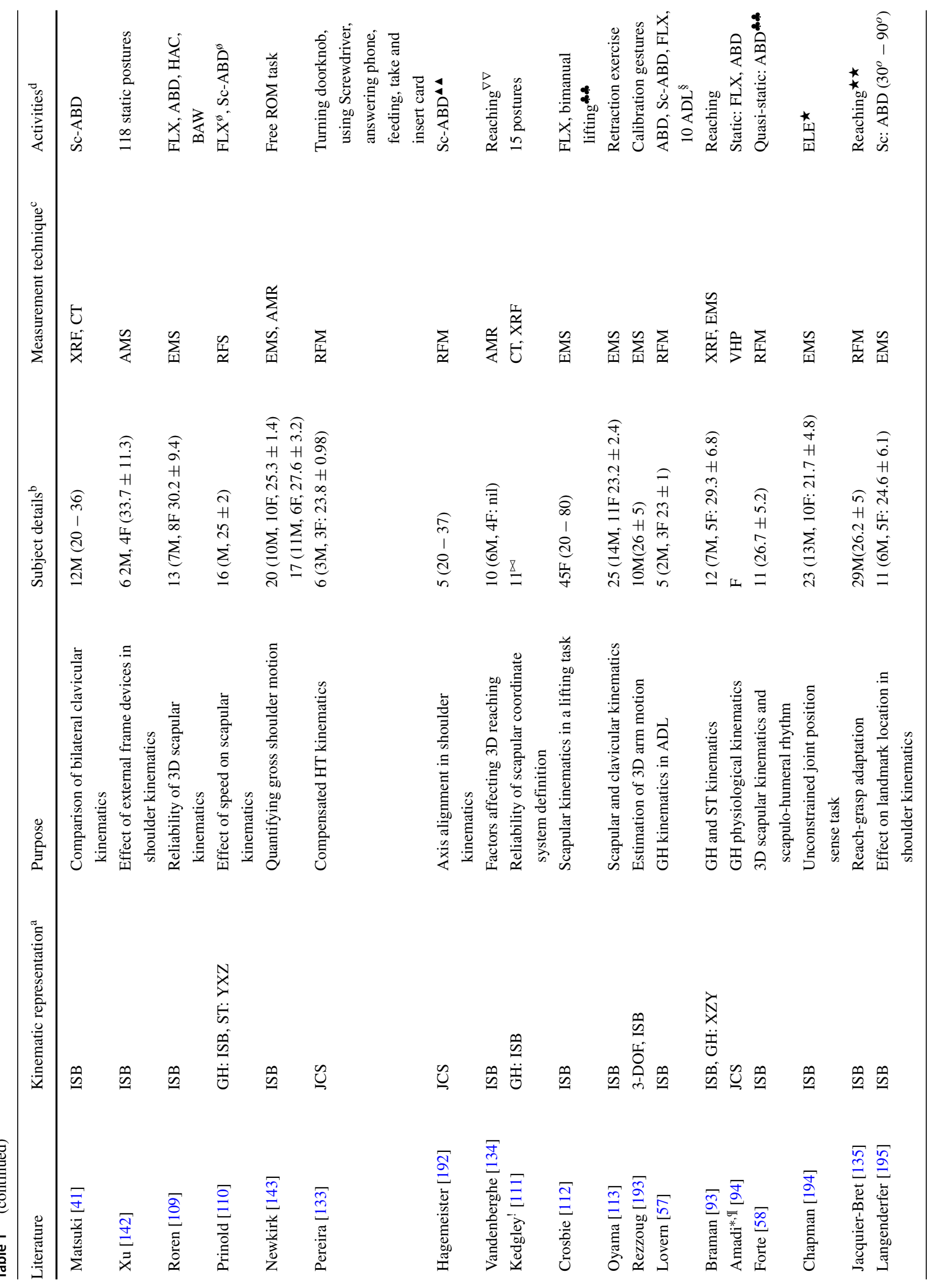




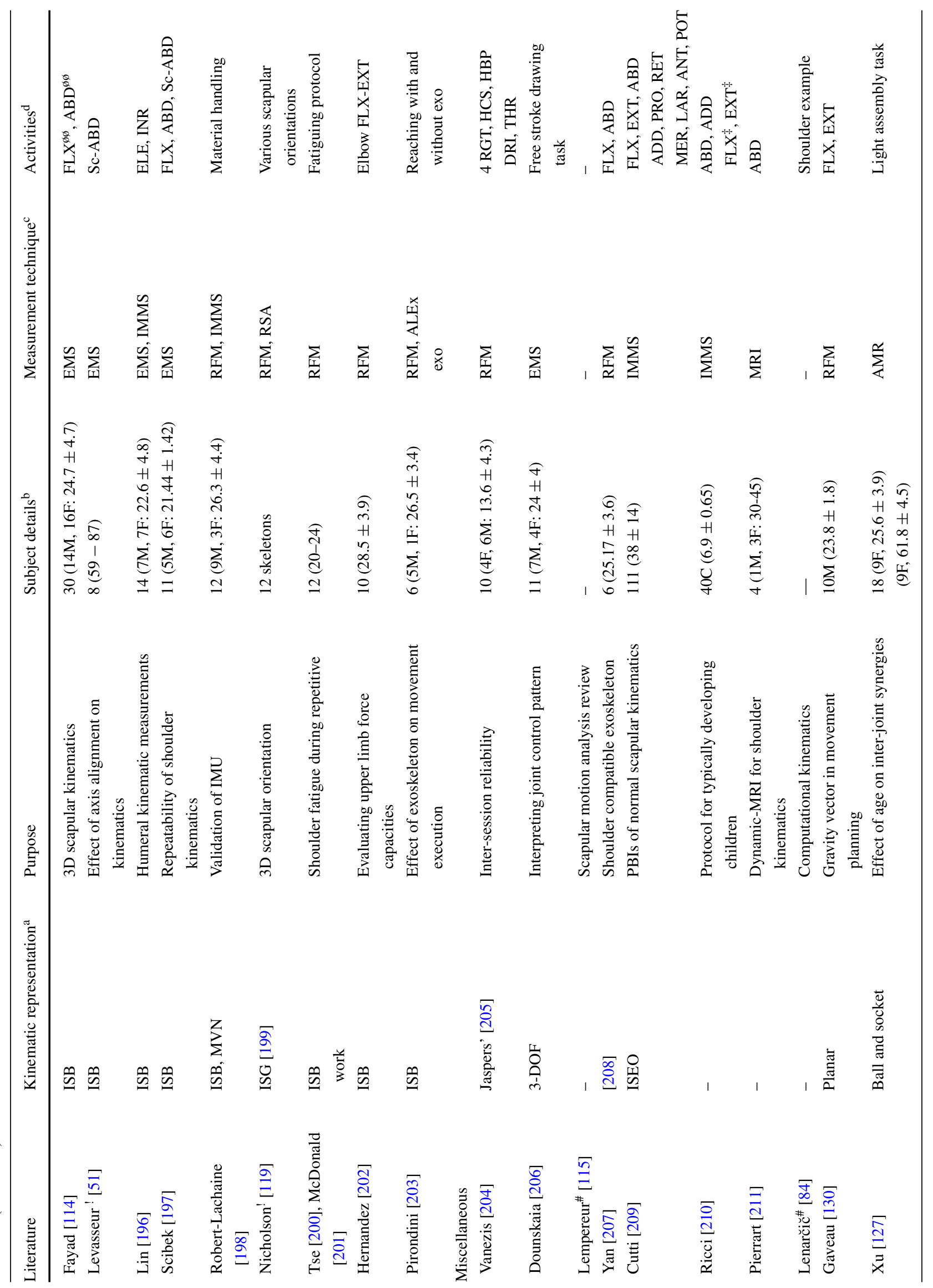




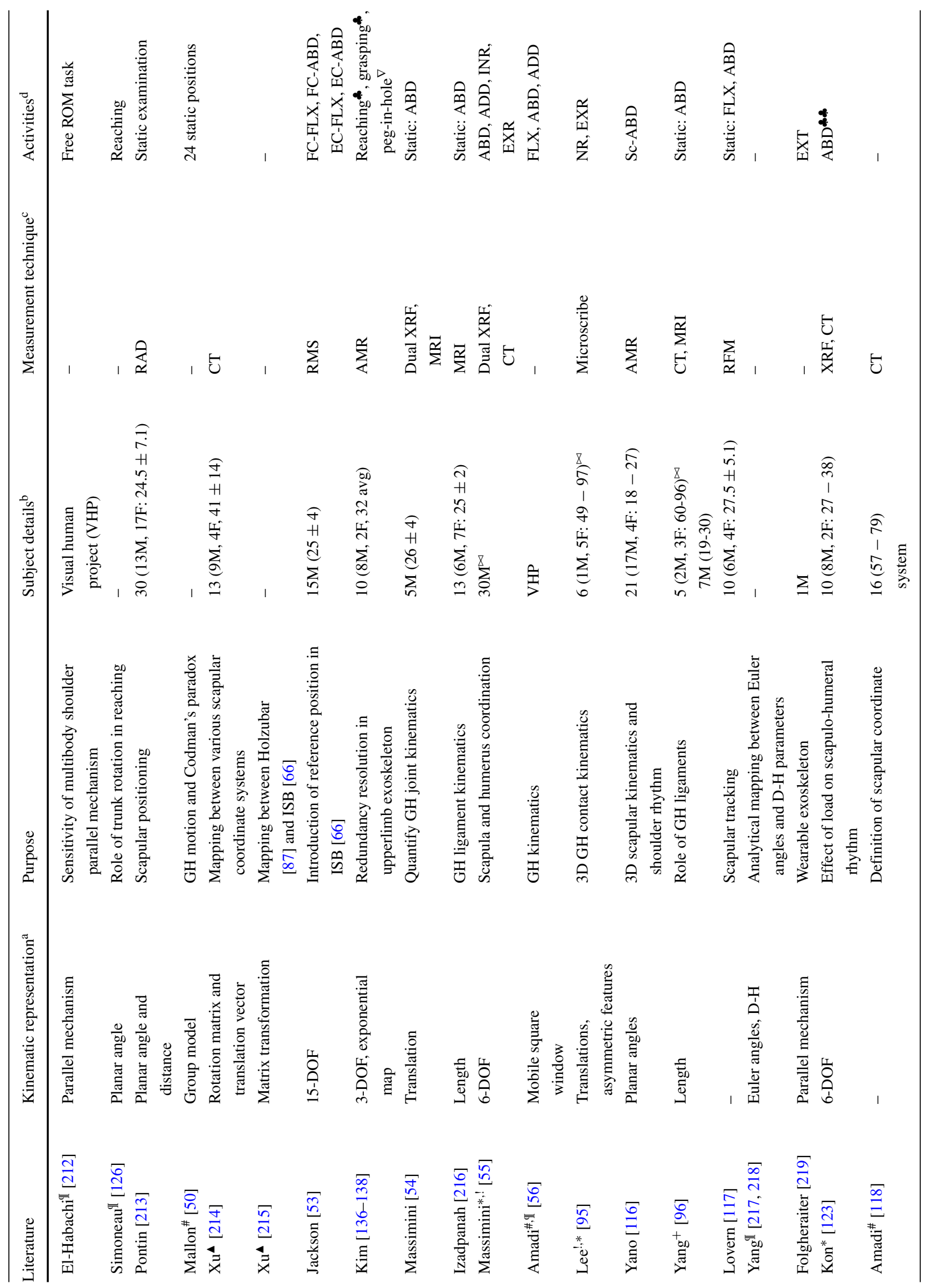




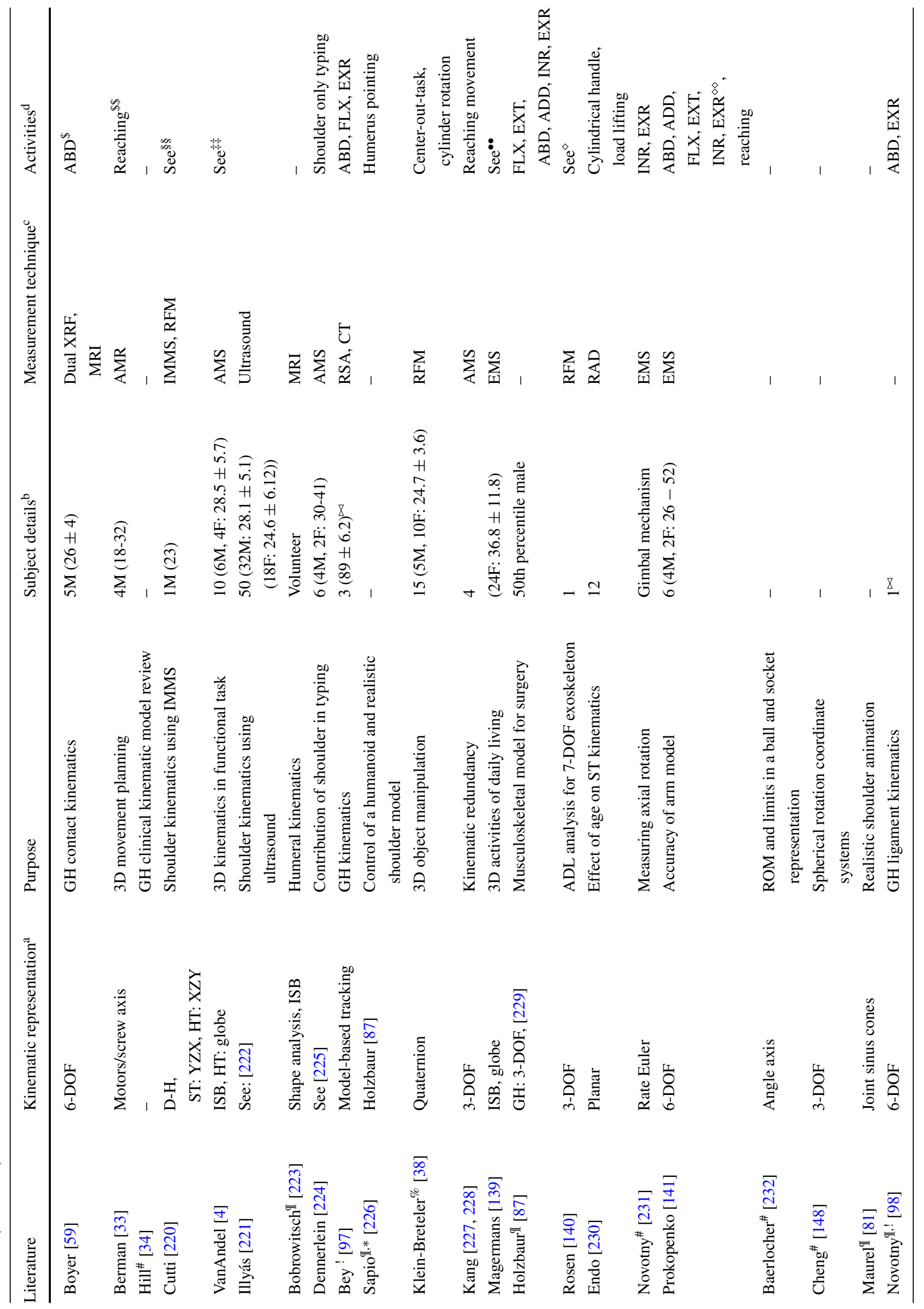




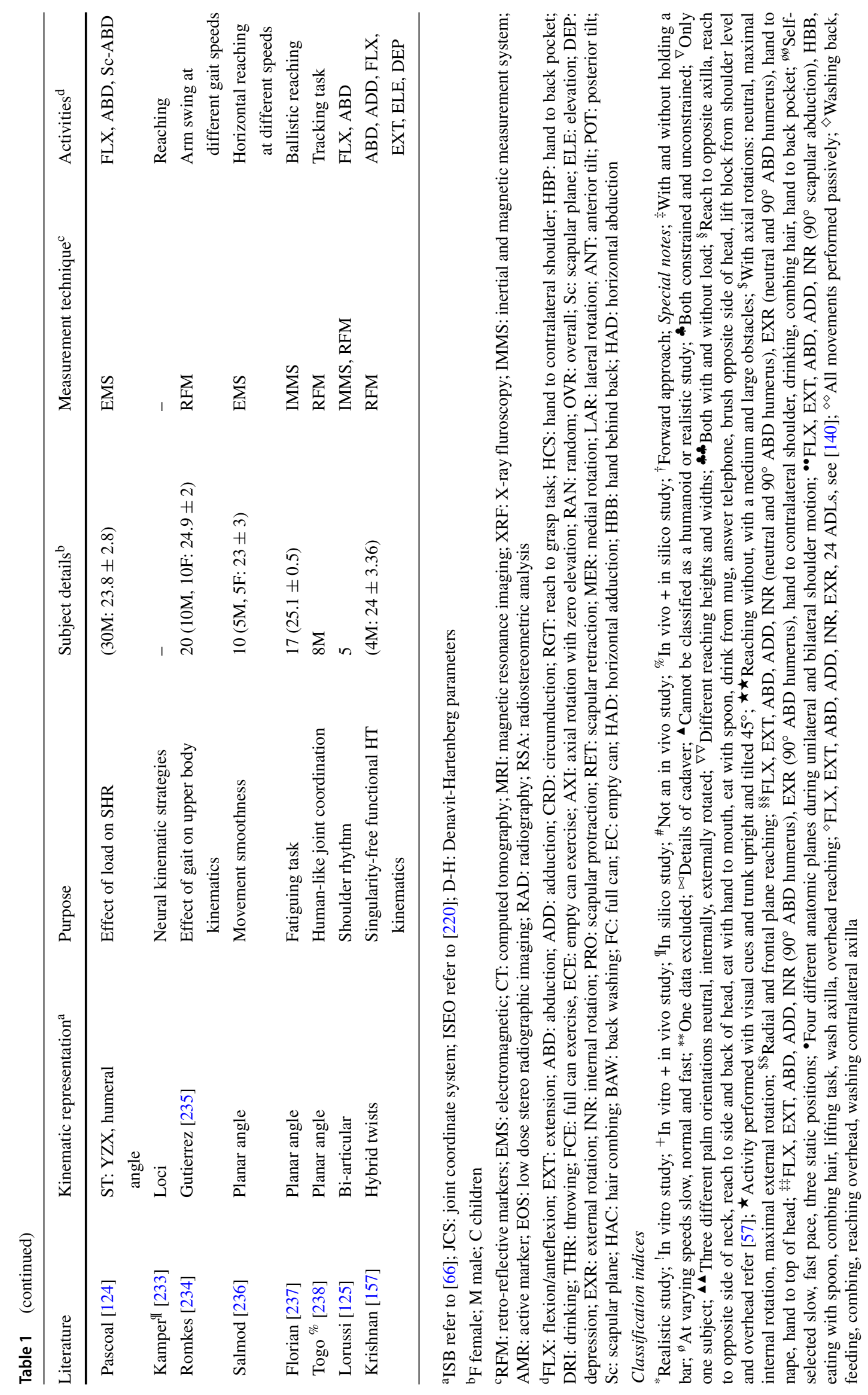




\section{References}

1. Turvey MT, Fonseca S (2009) Nature of motor control: perspectives and issues. Prog Mot Control A Multidiscip Perspect 629(585):93-123. https://doi.org/10.1007/978-0-387-77064-2_6

2. Tondu B (2007) Estimating shoulder-complex mobility. Appl Bionics Biomech 4(1):19-29. https://doi.org/10.1080/117623 20701403922

3. Alt Murphy M, Häger CK (2015) Kinematic analysis of the upper extremity after stroke-how far have we reached and what have we grasped? Phys Ther Rev 20(3):137-155. https://doi.org/ 10.1179/1743288X15Y.0000000002

4. van Andel CJ, Wolterbeek N, Doorenbosch CA, Veeger DH, Harlaar J (2008) Complete 3D kinematics of upper extremity functional tasks. Gait Posture 27(1):120-127. https://doi.org/ 10.1016/j.gaitpost.2007.03.002

5. Rockwood C, Writh MA, Matsen FA, Lippitt SB (2004) The shoulder, 4th edn, vol 1. Saunders, Philadelphia

6. Williams S, Schmidt R, Disselhorst-Klug C, Rau G (2006) An upper body model for the kinematical analysis of the joint chain of the human arm. J Biomech 39(13):2419-2429. https://doi.org/ 10.1016/j.jbiomech.2005.07.023

7. Demircan E, Kulic D, Oetomo D, Hayashibe M (2015) Human movement understanding [TC spotlight]. IEEE Robot Autom Mag 22(3):22-24. https://doi.org/10.1109/MRA.2015.2452171

8. Laumond J-P (2015) Robotics: Hephaestus is starting all over again. La Lett du Collège Fr (7):29. https://doi.org/ 10.4000/lettre-cdf.2641

9. Burdet E, Franklin DW, Milner TE (2013) Human roboticsneuromechanics and motor control. The MIT Press, Cambridge

10. Maurel W, Thalmann D (1999) A case study on human upper limb modelling for dynamic simulation. Comput Methods Biomech Biomed Eng 2(1):65-82. https://doi.org/10.1080/ 10255849908907979

11. Kulic D, Venture G, Yamane K, Demircan E, Mizuuchi I, Mombaur K (2016) Anthropomorphic movement analysis and synthesis: a survey of methods and applications. IEEE Trans Robot 32(4):776-795. https://doi.org/10.1109/TRO.2016.2587744

12. Jarrassé N, Proietti T, Crocher V, Robertson J, Sahbani A, Morel G, Roby-Brami A (2014) Robotic exoskeletons: a perspective for the rehabilitation of arm coordination in stroke patients. Front Hum Neurosci 8:1-13. https://doi.org/10.3389/fnhum.2014.00947

13. Jarrassé N, Morel G (2010) A formal method for avoiding hyperstaticity when connecting an exoskeleton to a human member. In: IEEE international conference on robotics and automation, pp 1188-1195. https://doi.org/10.1109/ROBOT.2010.5509346

14. Cortés C, Ardanza A, Molina-Rueda F, Cuesta-Gómez A, Unzueta L, Epelde G, Ruiz OE, De Mauro A, Florez J (2014) Upper limb posture estimation in robotic and virtual reality-based rehabilitation. Biomed Res Int. 1-18. https://doi.org/10.1155/2014/821908

15. Nordin N, Xie S, Wünsche B (2014) Assessment of movement quality in robot-assisted upper limb rehabilitation after stroke: a review. J Neuroeng Rehabil 11(1):137. https://doi.org/ 10.1186/1743-0003-11-137

16. der Loos HV, Reinkensmeyer DJ (2008) Rehabilitation and health care robotics. In: Springer handbook of robotics, pp 1223-1251. https://doi.org/10.1007/978-3-540-30301-5_54

17. Lobo-Prat J, Kooren PN, Stienen AH, Herder JL, Koopman BF, Veltink PH (2014) Non-invasive control interfaces for intention detection in active movement-assistive devices. J Neuroeng Rehabil 11(1):168. https://doi.org/10.1186/1743-0003-11-168

18. Gopura R, Bandara D, Kiguchi K, Mann G (2016) Developments in hardware systems of active upper-limb exoskeleton robots: a review. Robot Auton Syst 75:203-220. https://doi.org/ 10.1016/j.robot.2015.10.001
19. Lo HS, Xie SQ (2012) Exoskeleton robots for upper-limb rehabilitation: state of the art and future prospects. Med Eng Phys 34(3):261-268. https://doi.org/10.1016/j.medengphy.2011.10.004

20. Maciejasz P, Eschweiler J, Gerlach-Hahn K, Jansen-Troy A, Leonhardt S (2014) A survey on robotic devices for upper limb rehabilitation. J Neuroeng Rehabil 11(1):3. https://doi.org/ 10.1186/1743-0003-11-3

21. Pons JL (2008) Wearable robots: biomechatronic exoskeletons. Wiley, New York. https://doi.org/10.1002/9780470987667

22. Mutlu B, Roy N, Šabanović S (2016) Cognitive human-robot interaction. In: Springer handbook of robotics, pp 1907-1934. https://doi.org/10.1007/978-3-319-32552-1_71

23. Pons JL (2010) Rehabilitation exoskeletal robotics. IEEE Eng Med Biol Mag 29(3):57-63. https://doi.org/10.1109/MEMB. 2010.936548

24. Khatib O, Demircan E, De Sapio V, Sentis L, Besier T, Delp S (2009) Robotics-based synthesis of human motion. J Physiol Paris 103(3-5):211-219. https://doi.org/10.1016/ j.jphysparis.2009.08.004

25. Proietti T, Crocher V, Roby-Brami A, Jarrasse N (2016) Upper-limb robotic exoskeletons for neurorehabilitation: a review on control strategies. IEEE Rev Biomed Eng 9:4-14. https://doi.org/10.1109/RBME.2016.2552201

26. Turchetti G, Vitiello N, Trieste L, Romiti S, Geisler E, Micera S (2014) Why effectiveness of robot-mediated neurorehabilitation does not necessarily influence its adoption. IEEE Rev Biomed Eng 7:143-153. https://doi.org/10.1109/RBME.2014.2300234

27. Dipietro L, Krebs HI, Fasoli SE, Volpe BT, Hogan N (2009) Submovement changes characterize generalization of motor recovery after stroke. Cortex 45(3):318-324. https://doi.org/10.1016/j.cortex.2008.02.008

28. Lambercy O, Maggioni S, Lünenburger L, Gassert R, Bolliger M (2016) Robotic and wearable sensor technologies for measurements/clinical assessments. Neurorehabil Technol 183-207. https://doi.org/10.1007/978-3-319-28603-7_10

29. Krebs H, Volpe B (2013) Rehabilitation robotics. Neurol Rehabil 110:283-294. https://doi.org/10.1016/B978-0-44452901-5.00023-X

30. Borzelli D, Pastorelli S, Gastaldi L (2017) Elbow musculoskeletal model for industrial exoskeleton with modulated impedance based on operator's arm stiffness. IJAT 11:442-449

31. Dempster WT (1965) Mechanisms of shoulder movement. Arch Phys Med Rehabil 46:49-70

32. Veeger H, van der Helm F (2007) Shoulder function: the perfect compromise between mobility and stability. J Biomech 40(10):2119-2129. https://doi.org/10.1016/ j.jbiomech.2006.10.016

33. Berman S, Liebermann DG, Flash T (2008) Application of motor algebra to the analysis of human arm movements. Robotica 26(4):435-451. https://doi.org/10.1017/S0263574707003979

34. Hill A, Bull A, Wallace A, Johnson G (2008) Qualitative and quantitative descriptions of glenohumeral motion. Gait Posture 27(2):177-188. https://doi.org/10.1016/j.gaitpost.2007.04.008

35. Borzelli D, Gastaldi L, Bignardi C, Audenino A, Terzini M, Sard A, Pastorelli S (2017) Method for measuring the displacement of cadaveric elbow after the section of medial collateral ligament anterior and posterior bundles. In: Advances in service and industrial robotics, pp 972-979. https://doi.org/10.1007/978-3-319-61276-8_104

36. Sternad D, Park S-W, Müller H, Hogan N (2010) Coordinate dependence of variability analysis. PLoS Comput Biol 6(4):e1000751. https://doi.org/10.1371/journal.pcbi.1000751

37. Viceconti M (2011) Multiscale modeling of the skeletal system. Cambridge University Press, Cambridge. https://doi.org/10.1017/ CBO9781139049627 
38. Breteler MDK, Meulenbroek RGJ (2006) Modeling 3D object manipulation: synchronous single-axis joint rotations? Exp Brain Res 168(3):395-409. https://doi.org/10.1007/s00221-005-0107-x

39. Gielen C, van Bolhuis B, Theeuwen M (1995) On the control of biologically and kinematically redundant manipulators. Hum Mov Sci 14(4-5):487-509. https://doi.org/10.1016/ 0167-9457(95)00025-X

40. Peat M (1986) Functional anatomy of the shoulder complex. Phys Ther 66(12):1855-1865. https://doi.org/10.1093/ptj/66.12.1855

41. Matsuki K, Matsuki KO, Mu S, Kenmoku T, Yamaguchi S, Ochiai N, Sasho T, Sugaya H, Toyone T, Wada Y, Takahashi $\mathrm{K}$, Banks SA (2014) In vivo 3D analysis of clavicular kinematics during scapular plane abduction: comparison of dominant and non-dominant shoulders. Gait Posture 39(1):625627. https://doi.org/10.1016/j.gaitpost.2013.06.021

42. Inman V, Saunders M, Abbott L (1944) Observations on the function of the shoulder joint. J Bone Joint Surg 26 (1): $1-30$

43. Sah S, Wang X (2009) Determination of geometric constraints between the ribcage and scapula in the shoulder complex: a cadaver study. Comput Methods Biomech Biomed Eng 12(S1):223-224. https://doi.org/10.1080/10255840903093979

44. Garner BA, Pandy MG (1999) A kinematic model of the upper limb based on the visible human project (VHP) image dataset. Comput Methods Biomech Biomed Eng 2(2):107-124. https://doi.org/10.1080/10255849908907981

45. Seth A, Matias R, Veloso AP, Delp SL (2016) A biomechanical model of the scapulothoracic joint to accurately capture scapular kinematics during shoulder movements. PLoS One 11(1):e0141028. https://doi.org/10.1371/journal.pone.0141028

46. Haering D, Raison M, Begon M (2014) Measurement and description of three-dimensional shoulder range of motion with degrees of freedom interactions. J Biomech Eng 136(8):084502. https://doi.org/10.1115/1.4027665

47. Lippert LS (2011) Clinical kinesiology and anatomy, 5th edn. F. A. Davis Company, Philadelphia

48. Rau G, Disselhorst-Klug C, Schmidt R (2000) Movement biomechanics goes upwards: from the leg to the arm. J Biomech 33(10):1207-1216. https://doi.org/10.1016/S00219290(00)00062-2

49. Favre P, Snedeker JG, Gerbern C (2009) Numerical modelling of the shoulder for clinical applications. Philos Trans A Math Phys Eng Sci 367(1895):2095-2118. https://doi.org/10.1098/ rsta.2008.0282

50. Mallon WJ (2012) On the hypotheses that determine the definitions of glenohumeral joint motion: with resolution of Codman's pivotal paradox. J Shoulder Elbow Surg 21(12):e4-e19. https://doi.org/10.1016/j.jse.2011.05.029

51. Levasseur A, Tétreault P, de Guise J, Nuño N, Hagemeister N (2007) The effect of axis alignment on shoulder joint kinematics analysis during arm abduction. Clin Biomech 22(7):758-766. https://doi.org/10.1016/j.clinbiomech.2007.04.009

52. Charbonnier C, Chagué S, Kolo F, Chow J, Lädermann A (2014) A patient-specific measurement technique to model shoulder joint kinematics. Orthop Traumatol Surg Res 100(7):715-719. https://doi.org/10.1016/j.otsr.2014.06.015

53. Jackson M, Michaud B, Tétreault P, Begon M (2012) Improvements in measuring shoulder joint kinematics. J Biomech 45(12):2180-2183. https://doi.org/10.1016/j.jbiomech. 2012.05.042

54. Massimini DF, Boyer PJ, Papannagari R, Gill TJ, Warner JP, Li G (2012) In-vivo glenohumeral translation and ligament elongation during abduction and abduction with internal and external rotation. J Orthop Surg Res 7:29. https://doi.org/10.1186/ 1749-799X-7-29
55. Massimini DF, Warner JJ, Li G (2011) Non-invasive determination of coupled motion of the scapula and humerus - an in-vitro validation. J Biomech 44(3):408-412. https://doi.org/10.1016/ j.jbiomech.2010.10.003

56. Amadi HO, Bull AM (2010) A motion-decomposition approach to address gimbal lock in the 3-cylinder open chain mechanism description of a joint coordinate system at the glenohumeral joint. $J$ Biomech 43(16):3232-3236. https://doi.org/10.1016/j.jbiomech.2010.07.034

57. Lovern B, Stroud L, Ferran N, Evans S, Evans R, Holt C (2010) Motion analysis of the glenohumeral joint during activities of daily living. Comput Methods Biomech Biomed Eng 13(6):803809. https://doi.org/10.1080/10255841003630637

58. Forte FC, de Castro MP, de Toledo JM, Ribeiro DC, Loss JF (2009) Scapular kinematics and scapulohumeral rhythm during resisted shoulder abduction-implications for clinical practice. Phys Ther Sport 10(3):105-111. https://doi.org/10.1016/ j.ptsp.2009.05.005

59. Boyer PJ, Massimini DF, Gill TJ, Papannagari R, Stewart SL, Warner JP, Li G (2008) In vivo articular cartilage contact at the glenohumeral joint: preliminary report. J Orthop Sci 13(4):359365. https://doi.org/10.1007/s00776-008-1237-3

60. Begon M, Dal-Maso F, Arndt A, Monnet T (2015) Can optimal marker weightings improve thoracohumeral kinematics accuracy. J Biomech 48(10):2019-2025. https://doi.org/10.1016/ j.jbiomech.2015.03.023

61. Naaim A, Moissenet F, Dumas R, Begon M, Chèze L (2015) Comparison and validation of five scapulothoracic models for correcting soft tissue artefact through multibody optimisation. Comput Method Biomech Biomed Eng 18(sup1):2014-2015. https://doi.org/10.1080/10255842.2015.1069561

62. Duprey S, Naaim A, Moissenet F, Begon M, Chèze L Kinematic models of the upper limb joints for multibody kinematics optimisation: an overview. J Biomech. https://doi.org/10.1016/j.jbiomech.2016.12.005

63. Högfors C, Sigholm G, Herberts P (1987) Biomechanical model of the human shoulder-I-elements. J Biomech 20(2):157-166. https://doi.org/10.1016/0021-9290(87)90307-1

64. Karlsson D, Peterson B (1992) Towards a model for force predictions in the human shoulder. J Biomech 25(2):189-199. https://doi.org/10.1016/0021-9290(92)90275-6

65. Xu X, Lin J, McGorry RW (2014) A regression-based 3-D shoulder rhythm. J Biomech 47(5):1206-1210. https://doi.org/10.1016/ j.jbiomech.2014.01.043

66. Wu G, van der Helm FC, Veeger HD, Makhsous M, Roy PV, Anglin C et al (2005) ISB recommendation on definitions of joint coordinate systems of various joints for the reporting of human joint motion-part II: shoulder, elbow, wrist and hand. J Biomech 38(5):981-992. https://doi.org/10.1016/j.jbiomech.2004.05.042

67. Kontaxis A, Cutti A, Johnson G, Veeger H (2009) A framework for the definition of standardized protocols for measuring upper-extremity kinematics. Clin Biomech 24(3):246-253. https://doi.org/10.1016/j.clinbiomech.2008.12.009

68. Zatsiorsky VM (1998) Kinematics of human motion. Human Kinetics

69. Small C, Bryant J, Pichora D (1992) Rationalization of kinematic descriptors for three-dimensional hand and finger motion. J Biomed Eng 14(2):133-141. https://doi.org/10.1016/ 0141-5425(92)90018-G

70. van der Helm FC, Pronk GM (1995) Three-dimensional recording and description of motions of the shoulder mechanism. J Biomech Eng 117(1):27-40. https://doi.org/10.1115/1.2792267

71. Grood ES, Suntay WJ (1983) A joint coordinate system for the clinical description of three-dimensional motions: application to the knee. J Biomech Eng 105(2):136-144. https://doi.org/10.1115/1.3138397 
72. Macwilliams BA, Davis RB (2013) Addressing some misperceptions of the joint coordinate system. J Biomech Eng 135:54506. https://doi.org/10.1115/1.4024142

73. Spong MW, Hutchinson S, Vidyasagar M (2006) Robot modeling and control. Wiley, New York

74. Singh A, Singla A, Soni S (2015) Extension of D-H parameter method to hybrid manipulators used in robot-assisted surgery. Proc Inst Mech Eng H: J Eng Med 229(10):703-712. https://doi.org/10.1177/0954411915602289

75. Yang J, Feng X, Kim JH, Rajulu S (2010) Review of biomechanical models for human shoulder complex. Int J Hum Factors Model Simul 1:271. https://doi.org/10.1504/IJHFMS.2010.036791

76. Ingram D, Engelhardt C, Farron A, Terrier A, Mullhaupt $P$ (2013) A minimal set of coordinates for describing humanoid shoulder motion. In: 2013 IEEE/RSJ international conference on intelligent robots and systems, pp 5537-5544. https://doi.org/10.1109/IROS.2013.6697159

77. Lenarčič J, Stanišič M (2003) A humanoid shoulder complex and the humeral pointing kinematics. IEEE Trans Robot Autom 19(3):499-506. https://doi.org/10.1109/TRA.2003.810578

78. Pearl ML, Harris SL, Lippitt SB, Sidles JA, Harryman DT et al (1992) A system for describing positions of the humerus relative to the thorax and its use in the presentation of several functionally important arm positions. J Shoulder Elbow Surg 1(2):113-118. https://doi.org/10.1016/S1058-2746(09)80129-8

79. Doorenbosch CAM, Harlaar J, Veeger DHEJ (2003) The globe system: an unambiguous description of shoulder positions in daily life movements. J Rehabil Res Dev 40(2):147-155. https://doi.org/10.1682/JRRD.2003.03.0149

80. Engín AE (1980) On the biomechanics of the shoulder complex. J Biomech 13:575-590. https://doi.org/10.1016/0021-9290 (80)90058-5

81. Maurel W, Thalmann D (2000) Human shoulder modeling including scapulo-thoracic constraint and joint sinus cones. Comput Graph 24:203-218. https://doi.org/10.1016/ S0097-8493(99)00155-7

82. Naaim A, Moissenet F, Duprey S, Begon $M$, Chèze L. Effect of various upper limb multibody models on soft tissue artefact correction: a case study. J Biomech. https://doi.org/10.1016/j.jbiomech.2017.01.031

83. El-Habachi A, Duprey S, Cheze L, Dumas R (2015) A parallel mechanism of the shoulder-application to multibody optimisation. Multibody Syst Dyn 33(4):439-451. https://doi.org/10.1007/s11044-014-9418-7

84. Lenarçič J (2014) Some computational aspects of robot kinematic redundancy. In: Parallel problem solving from nature PPSN XIII, pp 1-10. https://doi.org/10.1007/978-3-319-10762-2_1

85. Massimini DF, Warner JJ, Li G (2014) Glenohumeral joint cartilage contact in the healthy adult during scapular plane elevation depression with external humeral rotation. J Biomech 47(12):3100-3106. https://doi.org/10.1016/ j.jbiomech.2014.06.034

86. Dao TT, Tho M-CHB (2014) Biomechanics of the musculoskeletal system: modeling of data uncertainty and knowledge. Wiley, Chichester. https://doi.org/10.1002/9781118930991

87. Holzbaur KRS, Murray WM, Delp SL (2005) A model of the upper extremity for simulating musculoskeletal surgery and analyzing neuromuscular control. Ann Biomed Eng 33(6):829840. https://doi.org/10.1007/s10439-005-3320-7

88. Dal-Maso F, Raison M, Lundberg A, Arndt A, Begon M (2014) Coupling between 3D displacements and rotations at the glenohumeral joint during dynamic tasks in healthy participants. Clin Biomech 29(9):1048-1055. https://doi.org/10.1016/ j.clinbiomech.2014.08.006
89. Lempereur M, Leboeuf F, Brochard. S, Rémy-Néris O (2014) Effects of glenohumeral joint centre mislocation on shoulder kinematics and kinetics. Comput Methods Biomech Biomed Eng 17(sup1):130-131. https://doi.org/10.1080/10255842.2014. 931539

90. Phadke V, Braman JP, LaPrade RF, Ludewig PM (2011) Comparison of glenohumeral motion using different rotation sequences. J Biomech 44(4):700-705. https://doi.org/10.1016/ j.jbiomech.2010.10.042

91. Šenk M, Chéze L (2006) Rotation sequence as an important factor in shoulder kinematics. Clin Biomech 21:S3-S8. https://doi.org/10.1016/j.clinbiomech.2005.09.007

92. An K-N, Browne AO, Korinek S, Tanaka S, Morrey BF (1991) Three-dimensional kinematics of glenohumeral elevation. J Orthop Res 9(1):143-149. https://doi.org/10.1002/ jor.1100090117

93. Braman JP, Engel SC, LaPrade RF, Ludewig PM (2009) In vivo assessment of scapulohumeral rhythm during unconstrained overhead reaching in asymptomatic subjects. J Shoulder Elb Surg 18(6):960-967. https://doi.org/10.1016/j.jse.2009.02.001

94. Amadi HO, Hansen UN, Bull AM (2009) A numerical tool for the reconstruction of the physiological kinematics of the glenohumeral joint. Proc Inst Mech Eng Part H: J Eng Med 223(7):833-837. https://doi.org/10.1016/S0021-9290(06)83203-3

95. Lee YS, Lee TQ (2010) Specimen-specific method for quantifying glenohumeral joint kinematics. Ann Biomed Eng 38(10):32263236. https://doi.org/10.1007/s10439-010-0074-7

96. Yang C, Goto A, Sahara W, Yoshikawa H, Sugamoto K (2010) In vivo three-dimensional evaluation of the functional length of glenohumeral ligaments. Clin Biomech 25(2):137-141. https://doi.org/10.1016/j.clinbiomech.2009.10.009

97. Bey MJ, Zauel R, Brock SK, Tashman S (2006) Validation of a new model-based tracking technique for measuring threedimensional, in vivo glenohumeral joint kinematics. J Biomech Eng 128(4):604-609. https://doi.org/10.1115/1.2206199

98. Novotny JE, Beynnon BD, Nichols CE (2000) Modeling the stability of the human glenohumeral joint during external rotation. J Biomech 33(3):345-354. https://doi.org/10.1016/S0021-9290(99)00142-6

99. van den Noort JC, Wiertsema SH, Hekman KMC, Schönhuth CP, Dekker J, Harlaar J (2014) Reliability and precision of 3D wireless measurement of scapular kinematics. Med Biol Eng Comput 52(11):921-931. https://doi.org/10.1007/s11517-014-1186-2

100. Worobey LA, Udofa IA, Lin Y-S, Koontz AM, Farrokhi SS, Boninger ML (2014) Reliability of freehand three-dimensional ultrasound to measure scapular rotations. J Rehabil Res Dev 51(6):985-994. https://doi.org/10.1682/JRRD.2014.01.0006

101. Brochard S, Lempereur M, Rémy-Néris O (2011) Double calibration: an accurate, reliable and easy-to-use method for 3D scapular motion analysis. J Biomech 44(4):751-754. https://doi.org/10.1016/j.jbiomech.2010.11.017

102. Bourne DA, Choo AM, Regan WD, MacIntyre DL, Oxland TR (2011) The placement of skin surface markers for non-invasive measurement of scapular kinematics affects accuracy and reliability. Ann Biomed Eng 39(2):777-785. https://doi.org/10.1007/s10439-010-0185-1

103. Borstad JD, Szucs K, Navalgund A (2009) Scapula kinematic alterations following a modified push-up plus task. Hum Mov Sci 28(6):738-751. https://doi.org/10.1016/j.humov.2009.05.002

104. Bourne DA, Choo AM, Regan WD, MacIntyre DL, Oxland TR (2009) A new subject-specific skin correction factor for threedimensional kinematic analysis of the scapula. J Biomech Eng 131(12):121009. https://doi.org/10.1115/1.4000284 
105. Dayanidhi S, Orlin M, Kozin S, Duff S, Karduna A (2005) Scapular kinematics during humeral elevation in adults and children. Clin Biomech 20(6):600-606. https://doi.org/10.1016/j.clinbiomech.2005.03.002

106. Thigpen C, Gross M, Karas S, Garrett W, Yu B (2005) The repeatability of scapular rotations across three planes of humeral elevation. Res Sport Med: Int J 13(3):181-198. https://doi.org/10.1080/15438620500222489

107. Fung M, Kato S, Barrance PJ, Elias JJ, McFarland EG, Nobuhara K, Chao EY (2001) Scapular and clavicular kinematics during humeral elevation: a study with cadavers. J Shoulder Elb Surg 10(3):278-285. https://doi.org/10.1067/mse.2001.114496

108. Myers J, Jolly J, Nagai T, Lephart S (2006) Reliability and precision of in vivo scapular kinematic measurements using an electromagnetic tracking device. J Sport Rehabil 15(2):125-143. https://doi.org/10.1123/jsr.15.2.125

109. Roren A, Fayad F, Roby-Brami A, Revel M, Fermanian J, Poiraudeau S, Robertson J, Lefevre-Colau M-M (2013) Precision of 3D scapular kinematic measurements for analytic arm movements and activities of daily living. Man Ther 18(6):473480. https://doi.org/10.1016/j.math.2013.04.005

110. Prinold JA, Villette CC, Bull AM (2013) The influence of extreme speeds on scapula kinematics and the importance of controlling the plane of elevation. Clin Biomech 28(9-10):973980. https://doi.org/10.1016/j.clinbiomech.2013.10.008

111. Kedgley AE, Dunning CE (2010) An alternative definition of the scapular coordinate system for use with RSA. J Biomech 43(8):1527-1531. https://doi.org/10.1016/ j.jbiomech.2010.01.043

112. Crosbie J, Kilbreath SL, Dylke E (2010) The kinematics of the scapulae and spine during a lifting task. J Biomech 43(7):13021309. https://doi.org/10.1016/j.jbiomech.2010.01.024

113. Oyama S, Myers JB, Wassinger CA, Lephart SM (2010) Threedimensional scapular and clavicular kinematics and scapular muscle activity during retraction exercises. J Ortho Sports Phys Ther 40(3):169-179. https://doi.org/10.2519/jospt.2010.3018

114. Fayad F, Hoffmann G, Hanneton S, Yazbeck C, Lefevrecolau M, Poiraudeau S, Revel MA (2006) Roby-Brami, 3D scapular kinematics during arm elevation: effect of motion velocity. Clin Biomech 21(9):932-941. https://doi.org/10.1016/ j.clinbiomech.2006.04.015

115. Lempereur M, Brochard S, Leboeuf F, Rémy-Néris O (2014) Validity and reliability of 3D marker based scapular motion analysis: a systematic review. J Biomech 47(10):2219-2230. https://doi.org/10.1016/j.jbiomech.2014.04.028

116. Yano Y, Hamada J, Tamai K, Yoshizaki K, Sahara R, Fujiwara T, Nohara Y (2010) Different scapular kinematics in healthy subjects during arm elevation and lowering: glenohumeral and scapulothoracic patterns. J Shoulder Elbow Surg 19(2):209-215. https://doi.org/10.1016/j.jse.2009.09.007

117. Lovern B, Stroud LA, Evans RO, Evans SL, Holt CA (2009) Dynamic tracking of the scapula using skin-mounted markers. J Eng Med 223:823-831. https://doi.org/10.1243/ 09544119JEIM554

118. Amadi HO, Hansen UN, Wallace AL, Bull AM (2008) A scapular coordinate frame for clinical and kinematic analyses. J Biomech 41(10):2144-2149. https://doi.org/10.1016/ j.jbiomech.2008.04.028

119. Nicholson KF, Richardson RT, Miller F, Richards JG (2017) Determining 3D scapular orientation with scapula models and biplane 2D images. Med Eng Phys 41:103-108. https://doi.org/10.1016/j.medengphy.2017.01.012

120. Robert-Lachaine X, Marion P, Godbout V, Bleau J, Begon M (2013) Elucidating the scapulo-humeral rhythm calculation: 3D joint contribution method. Comput Methods Biomech Biomed Eng 18(3):37-41. https://doi.org/10.1080/10255842.2013.792810

121. Parel I, Cutti AG, Kraszewski A, Verni G, Hillstrom H, Kontaxis A (2014) Intra-protocol repeatability and inter-protocol agreement for the analysis of scapulo-humeral coordination. Med Biol Eng Comput 52(3):271-282. https://doi.org/10.1007/ s11517-013-1121-y

122. Habechian FA, Fornasari GG, Sacramento LS, Camargo PR (2014) Differences in scapular kinematics and scapulohumeral rhythm during elevation and lowering of the arm between typical children and healthy adults. J Electromyogr Kinesiol 24(1):78-83. https://doi.org/10.1016/j.jelekin.2013.10.013

123. Kon Y, Nishinaka N, Gamada K, Tsutsui H, Banks SA (2008) The influence of handheld weight on the scapulohumeral rhythm. J Shoulder Elb Surg 17(6):943-946. https://doi.org/10.1016/ j.jse.2008.05.047

124. Pascoal AG, van der Helm F, Correia PP, Carita I (2000) Effects of different arm external loads on the scapulo-humeral rhythm. Clin Biomech 15(suppl 1):S21-S24. https://doi.org/10.1016/ S0268-0033(00)00055-3

125. Lorussi F, Carbonaro N, Rossi D D, Tognetti A A biarticular model for scapular-humeral rhythm reconstruction through data from wearable sensors. J NeuroEng Rehabil 13(1). https://doi.org/10.1186/s12984-016-0149-2

126. Simoneau M, Guillaud É, Blouin J (2013) Effects of underestimating the kinematics of trunk rotation on simultaneous reaching movements: predictions of a biomechanical model. J Neuroeng Rehabil 10(1):54. https://doi.org/10.1186/1743-0003-10-54

127. Xu X, Qin J, Catena RD, Faber GS, Lin J-H (2013) Effect of aging on inter-joint synergies during machine-paced assembly tasks. Exp Brain Res 231(2):249-256. https://doi.org/10.1007/ s00221-013-3688-9

128. Schwartz C, Croisier J-L, Rigaux E, Denoël V, Brüls O, Forthomme B (2014) Dominance effect on scapula 3dimensional posture and kinematics in healthy male and female populations. J Shoulder Elb Surg 23(6):873-881. https://doi.org/10.1016/j.jse.2013.08.020

129. van Kordelaar J, van Wegen EEH, Nijland RHM, Daffertshofer A, Kwakkel G (2013) Understanding adaptive motor control of the paretic upper limb early poststroke: the EXPLICITstroke program. Neurorehabil Neural Repair 27(9):854-863. https://doi.org/10.1177/1545968313496327

130. Gaveau J, Berret B, Demougeot L, Fadiga L, Pozzo T, Papaxanthis C (2014) Energy-related optimal control accounts for gravitational load: comparing shoulder, elbow, and wrist rotations. J Neurophysiol 111:4-16. https://doi.org/10.1152/jn.01029.2012

131. Qin J, Lin J-H, Faber GS, Buchholz B, Xu X (2014) Upper extremity kinematic and kinetic adaptations during a fatiguing repetitive task. J Electromyogr Kinesiol 24(3):404-411. https://doi.org/10.1016/j.jelekin.2014.02.001

132. Rundquist PJ, Obrecht C, Woodruff L (2009) Threedimensional shoulder kinematics to complete activities of daily living. Am J Phys Med Rehabil 88(8):623-629. https://doi.org/10.1097/PHM.0b013e3181ae0733

133. Pereira BP, Thambyah A, Lee T (2012) Limited forearm motion compensated by thoracohumeral kinematics when performing tasks requiring pronation and supination. J Appl Biomech 28(2):127-138. https://doi.org/10.1123/jab.28.2.127

134. Vandenberghe A, Levin O, De Schutter J, Swinnen S, Jonkers I (2010) Three-dimensional reaching tasks: effect of reaching height and width on upper limb kinematics and muscle activity. Gait Posture 32(4):500-507. https://doi.org/10.1016/j.gaitpost.2010.07.009 
135. Jacquier-Bret J, Rezzoug N, Gorce P (2009) Adaptation of joint flexibility during a reach-to-grasp movement. Motor Control 13(3):342-361. https://doi.org/10.1123/mcj.13.3.342

136. Kim H, Miller LM, Al-Refai A, Brand M, Rosen J (2011) Redundancy resolution of a human arm for controlling a seven DOF wearable robotic system. In: Proceedings. Annual international conference of the IEEE engineering in medicine and biology society EMBS, pp 34713474. https://doi.org/10.1109/IEMBS.2011.6090938

137. Kim H, Miller LM, Byl N, Abrams G, Rosen J (2012) Redundancy resolution of the human arm and an upper limb exoskeleton. IEEE Trans Biomed Eng 59(6):1770-1779. https://doi.org/10.1109/TBME.2012.2194489

138. Kim H, Li Z, Milutinović D, Rosen J (2012) Resolving the redundancy of a seven DOF wearable robotic system based on kinematic and dynamic constraint. In: 2012 IEEE international conference on robotics and automation, pp 305-310. https://doi.org/10.1109/ICRA.2012.6224830

139. Magermans D, Chadwick E, Veeger $H$, van der Helm F (2005) Requirements for upper extremity motions during activities of daily living. Clin Biomech 20(6):591-599. https://doi.org/10.1016/j.clinbiomech.2005.02.006

140. Rosen J, Perry J, Manning N, Burns S, Hannaford B (2005) The human arm kinematics and dynamics during daily activitiestoward a 7 DOF upper limb powered exoskeleton. In: 12th International conference on advanced robotics, pp 532-539

141. Prokopenko R, Frolov A, Biryukova E, Roby-Brami A (2001) Assessment of the accuracy of a human arm model with seven degrees of freedom. J Biomech 34(2):177-185. https://doi.org/10.1016/S0021-9290(00)00179-2

142. Xu X, McGorry RW, Lin J (2014) The accuracy of an external frame using ISB recommended rotation sequence to define shoulder joint angle. Gait Posture 39(1):662-668. https://doi.org/10.1016/j.gaitpost.2013.08.032

143. Newkirk JT, Tomsic M, Crowell CR, Villano MA, Stanisic MM (2013) Measurement and quantification of gross human shoulder motion. Appl Bionics Biomech 10:159-173. https://doi.org/10.3233/ABB-140083

144. Schiele A, van der Helm FCT (2006) Kinematic design to improve ergonomics in human machine interaction. IEEE Trans Neural Syst Rehabil Eng 14(4):456-469. https://doi.org/10.1109/ TNSRE.2006.881565

145. Schomacher J (2009) The convex-concave rule and the lever law. Man Ther 14(5):579-582. https://doi.org/10.1016/ j.math.2009.01.005

146. Brandt C, Sole G, Krause MW, Nel M (2007) An evidencebased review on the validity of the Kaltenborn rule as applied to the glenohumeral joint. Man Ther 12(1):3-11. https://doi.org/ 10.1016/j.math.2006.02.011

147. Cattrysse E, Baeyens J-P, Van Roy P, Van de Wiele O, Roosens T, Clarys J-P. Intra-articular kinematics of the upper limb joints: a six degrees of freedom study of coupled motions. Ergonomics 48(1114):1657-1671. https://doi.org/10.1080/00140130500101189

148. Cheng PL (2000) A spherical rotation coordinate system for the description of three-dimensional joint rotations. Ann Biomed Eng 28(11):1381-1392. https://doi.org/10.1114/1.1326030

149. Koks D (2006) A roundabout route to geometric algebra. In: Explorations in mathematical physics: the concepts behind an elegant language, pp 147-184. https://doi.org/ 10.1007/978-0-387-32793-8_4

150. Michaud B, Jackson MI, Prince F, Begon MS (2014) Can one angle be simply subtracted from another to determine range of motion in three-dimensional motion analysis? Comput Methods Biomech Biomed Eng 17(5):507-515. https://doi.org/10.1080/10255842.2012.696104
151. Krebs HI, Krams M, Agrafiotis DK, DiBernardo A, Chavez JC, Littman GS, Yang E, Byttebier G, Dipietro L, Rykman A, McArthur K, Hajjar K, Lees KR, Volpe BT (2013) Robotic measurement of arm movements after stroke establishes biomarkers of motor recovery. Stroke 45(1):200-204. https://doi.org/10.1161/strokeaha.113.002296

152. Krebs HI, Saitoh E, Hogan N (2015) Robotic therapy and the paradox of the diminishing number of degrees of freedom. Phys Med Rehabil Clin N Am 26(4):691-702. https://doi.org/10.1016/ j.pmr.2015.06.003

153. McGinley JL, Baker R, Wolfe R, Morris ME (2009) The reliability of three-dimensional kinematic gait measurements: a systematic review. Gait Posture 29(3):360-369. https://doi.org/10.1016/j.gaitpost.2008.09.003

154. Scholz JP, Schöner G (1999) The uncontrolled manifold concept: identifying control variables for a functional task. Exp Brain Res 126(3):289-306. https://doi.org/10.1007/s002210050738

155. Reinkensmeyer DJ, Burdet E, Casadio M, Krakauer JW, Kwakkel G, Lang CE, Swinnen SP, Ward NS, Schweighofer N (2016) Computational neurorehabilitation: modeling plasticity and learning to predict recovery. J Neuroeng Rehabil 13(1):42. https://doi.org/10.1186/s12984-016-0148-3

156. Davidson JK, Hunt KH (2004) Robots and screw theory: applications of kinematics and statics to robotics. Oxford University Press, New York

157. Krishnan R, Björsell N, Smith C (2016) Invariant spatial parametrization of human thoracohumeral kinematics: a feasibility study. 2016 IEEE/RSJ. In: International conference on intelligent robots and systems, pp 4469-4476. https://doi.org/10.1109/IROS.2016.7759658

158. Chow JW, Knudson DV (2011) Use of deterministic models in sports and exercise biomechanics research. Sport Biomech 10(3):219-233. https://doi.org/10.1080/14763141.2011.592212

159. Schmitz A, Buczek FL, Bruening D, Rainbow MJ, Cooney K, Thelen D (2015) Comparison of hierarchical and six degrees-of-freedom marker sets in analyzing gait kinematics. Comput Methods Biomech Biomed Eng 19(2):199-207. https://doi.org/10.1080/10255842.2015.1006208

160. Buczek FL, Rainbow MJ, Cooney KM, Walker MR, Sanders JO (2010) Implications of using hierarchical and six degree-offreedom models for normal gait analyses. Gait Posture 31(1):5763. https://doi.org/10.1016/j.gaitpost.2009.08.245

161. Glazier PS, Robins MT (2012) Comment on "Use of deterministic models in sports and exercise biomechanics research" by Chow and Knudson (2011). Sport Biomech 11(1):120-122. https://doi.org/10.1080/14763141.2011.650189

162. Seáñez-González I, Mussa-Ivaldi FA (2014) Cursor control by Kalman filter with a non-invasive body-machine interface. J Neural Eng 11(5):056026. https://doi.org/10.1088/1741-2560/11/5/056026

163. Zhu Z, Massimini DF, Wang G, Warner JJ, Li G (2012) The accuracy and repeatability of an automatic 2D-3D fluoroscopic image-model registration technique for determining shoulder joint kinematics. Med Eng Phys 34(9):1303-1309. https://doi.org/10.1016/j.medengphy.2011.12.021

164. Tsai C-Y, Lin C-J, Huang Y-C, Lin P-C, Su F-C (2012) The effects of rear-wheel camber on the kinematics of upper extremity during wheelchair propulsion. Biomed Eng Online 11(1):87. https://doi.org/10.1186/1475-925X-11-87

165. Shaheen A, Alexander C, Bull A (2011) Tracking the scapula using the scapula locator with and without feedback from pressure-sensors: a comparative study. J Biomech 44(8):16331636. https://doi.org/10.1016/j.jbiomech.2011.02.139

166. Billuart F, Devun L, Skalli W, Mitton D, Gagey O (2008) Role of deltoid and passives elements in stabilization during abduction 
motion (0 degrees-40 degrees): an ex vivo study. Surg Radiol Anat 30(7):563-568. https://doi.org/10.1007/s00276-008-0374-x

167. Teece RM, Lunden JB, Lloyd AS, Kaiser AP, Cieminski CJ, Ludewig PM (2008) Three-dimensional acromioclavicular joint motions during elevation of the arm. J Orthop Sport Phys Ther 38(4):181-190. https://doi.org/10.2519/jospt.2008.2386

168. Sahara W, Sugamoto K, Murai M, Tanaka H, Yoshikawa $\mathrm{H}$ (2007) The three-dimensional motions of glenohumeral joint under semi-loaded condition during arm abduction using vertically open MRI. Clin Biomech 22(3):304-312. https://doi.org/10.1016/j.clinbiomech.2006.04.012

169. Sahara W, Sugamoto K, Murai M, Tanaka H, Yoshikawa H (2006) 3D kinematic analysis of the acromioclavicular joint during arm abduction using vertically open MRI. J Orthop Res 24(9):1823-1831. https://doi.org/10.1002/jor.20208

170. Sahara W, Sugamoto K, Murai M, Yoshikawa H (2007) Threedimensional clavicular and acromioclavicular rotations during arm abduction using vertically open MRI. J Orthop Res 25(9):12431249. https://doi.org/10.1002/jor.20407

171. Meskers C, van der Helm F, Rozendaal L, Rozing P (1997) In vivo estimation of the glenohumeral joint rotation center from scapular bony landmarks by linear regression. J Biomech 31(1):93-96. https://doi.org/10.1016/S0021-9290(97)00101-2

172. Karduna AR, McClure PW, Michener LA (2000) Scapular kinematics: effects of altering the Euler angle sequence of rotations. J Biomech 33(9):1063-1068. https://doi.org/ 10.1016/S0021-9290(00)00078-6

173. Zhang Q, Liu R, Chen W, Xiong C Simultaneous and continuous estimation of shoulder and elbow kinematics from surface EMG signals. Front Neurosci 11. https://doi.org/ 10.3389/fnins.2017.00280

174. Robert-Lachaine X, Mecheri H, Larue C, Plamondon A (2017) Accuracy and repeatability of single-pose calibration of inertial measurement units for whole-body motion analysis. Gait Posture 54:80-86. https://doi.org/10.1016/j.gaitpost.2017.02.029

175. Borbély BJ, Szolgay $P$ Real-time inverse kinematics for the upper limb: a model-based algorithm using segment orientations. BioMed Eng OnLine 16 (1). https://doi.org/10.1186/s12938-016-0291-x

176. López-Pascual J, Cáceres ML, Rosario HD, Page Á (2016) The reliability of humerothoracic angles during arm elevation depends on the representation of rotations. J Biomech 49(3):502-506. https://doi.org/10.1016/j.jbiomech.2015.12.045

177. de Vries W, Veeger H, Cutti A, Baten C, van der Helm v (2010) Functionally interpretable local coordinate systems for the upper extremity using inertial \& magnetic measurement systems. J Biomech 43(10):1983-1988. https://doi.org/ 10.1016/j.jbiomech.2010.03.007

178. Rosado J, Silva F, Santos V, Lu Z (2013) Reproduction of human arm movements using Kinect-based motion capture data. In: 2013 IEEE international conference on robotics and biomimetics (ROBIO), pp 885-90. https://doi.org/ 10.1109/ROBIO.2013.6739574

179. El-Gohary M, McNames J (2012) Shoulder and elbow joint angle tracking with inertial sensors. IEEE Trans Bio-med Eng 59(9):2635-2641. https://doi.org/10.1109/TBME.2012.2208750

180. Zhang Z-Q, Wong W-C, Wu J-K (2011) Ubiquitous human upper-limb motion estimation using wearable sensors. IEEE Trans Inf Technol Biomed 15(4):513-521. https://doi.org/10.1109/TITB.2011.2159122

181. Lv P, Zhang M, Xu M, Li H, Zhu P, Pan Z (2011) Biomechanicsbased reaching optimization. Vis Comput 27(6-8):613-621. https://doi.org/10.1007/s00371-011-0568-9

182. Kundu SK, Yamamoto A, Hara M, Higuchi T (2010) Estimation of human operational feeling level for a lever manipulation task using shoulder angle and manipulability. 2010 IEEE international conference on systems, man, and cybernetics, pp 1918-1924. https://doi.org/10.1109/ICSMC.2010.5642268

183. Lenarcic J, Umek A (1994) Simple model of human arm reachable workspace. IEEE Trans Syst Man Cybern 24(8):12391246. https://doi.org/10.1109/21.299704

184. Klopčar N, Tomšič M, Lenarčič J (2007) A kinematic model of the shoulder complex to evaluate the armreachable workspace. J Biomech 40(1):86-91. https://doi.org/ 10.1016/j.jbiomech.2005.11.010

185. Lenarcic J, Klopcar N (2005) Positional kinematics of humanoid arms. Robotica 24(01):105. https://doi.org/ 10.1017/S0263574705001906

186. Klopćar N, Lenarcić J (2006) Bilateral and unilateral shoulder girdle kinematics during humeral elevation. Clin Biomech 21:S20-S26. https://doi.org/10.1016/j.clinbiomech.2005.09.009

187. Liu W, Chen D, Steil J (2016) Analytical inverse kinematics solver for anthropomorphic 7-DOF redundant manipulators with human-like configuration constraints. J Intell Robot Syst 86(1):63-79. https://doi.org/10.1007/s10846-016-0449-6

188. Kashima T, Hori K (2016) Control of biomimetic robots based on analysis of human arm trajectories in 3D movements. Artif Life Robot 21(1):24-30. https://doi.org/10.1007/s10015-015-0244-7

189. Laitenberger M, Raison M, Périé D, Begon M (2014) Refinement of the upper limb joint kinematics and dynamics using a subjectspecific closed-loop forearm model. Multibody Sys Dyn. 413438. https://doi.org/10.1007/s11044-014-9421-z

190. Srinivasan D, Rudolfsson T, Mathiassen SE (2015) Between- and within-subject variance of motor variability metrics in females performing repetitive upper-extremity precision work. J Electromyogr Kinesiol 25(1):121-129. https://doi.org/10.1016/j.jelekin.2014.10.011

191. Bolsterlee B, Veeger HEJ, van der Helm FCT (2014) Modelling clavicular and scapular kinematics: from measurement to simulation. Med Biol Eng Comput 52(3):283-291. https://doi.org/10.1007/s11517-013-1065-2

192. Hagemeister N, Senk M, Dumas R, Chèze L (2011) Effect of axis alignment on in vivo shoulder kinematics. Comput Methods Biomech Biomed Eng 14(8):755-761. https://doi.org/10.1080/10255842.2010.493887

193. Rezzoug N, Jacquier-Bret J, Gorce P (2010) A method for estimating three-dimensional human arm movement with two electromagnetic sensors. Comput Methods Biomech Biomed Eng 13(6):663-668. https://doi.org/10.1080/10255840903405652

194. Chapman J, Suprak DN, Karduna AR (2009) Unconstrained shoulder joint position sense does not change with body orientation. J Orthop Res 27(7):885-890. https://doi.org/10.1002/jor.20813

195. Langenderfer JE, Rullkoetter PJ, Mell AG, Laz PJ (2009) A multi-subject evaluation of uncertainty in anatomical landmark location on shoulder kinematic description. Comput Methods Biomech Biomed Eng 12(2):211-216. https://doi.org/10.1080/10255840802372094

196. Lin Y-L, Karduna AR (2013) Sensors on the humerus are not necessary for an accurate assessment of humeral kinematics in constrained movements. J Appl Biomech 29(4):496-500. https://doi.org/10.1123/jab.29.4.496

197. Scibek JS, Carcia CR (2013) Validation and repeatability of a shoulder biomechanics data collection methodology and instrumentation. J Appl Biomech 29(5):609-616. https://doi.org/10.1123/jab.29.5.609

198. Robert-Lachaine X, Mecheri H, Larue C, Plamondon A (2016) Validation of inertial measurement units with an optoelectronic system for whole-body motion analysis. Med Biol Eng Comput 55(4):609-619. https://doi.org/10.1007/s11517-016-1537-2 
199. Wu G, Cavanagh PR (1995) ISB recommendations for standardization in the reporting of kinematic data. J Biomech 28(10):12571261. https://doi.org/10.1016/0021-9290(95)00017-c

200. Tse CT, McDonald AC, Keir PJ (2016) Adaptations to isolated shoulder fatigue during simulated repetitive work. Part I: fatigue. J Electromyogr Kinesiol 29:34-41. https://doi.org/10.1016/j.jelekin.2015.07.003

201. McDonald AC, Tse CT, Keir PJ (2016) Adaptations to isolated shoulder fatigue during simulated repetitive work. Part II: recovery. J Electromyogr Kinesiol 29:42-49. https://doi.org/10.1016/j.jelekin.2015.05.005

202. Hernandez V, Rezzoug N, Jacquier-Bret J, Gorce P (2015) Human upper-limb force capacities evaluation with robotic models for ergonomic applications: effect of elbow flexion. Comput Methods Biomech Biomed Eng 19(4):440-449. https://doi.org/10.1080/10255842.2015.1034117

203. Pirondini E, Coscia M, Marcheschi S, Roas G, Salsedo F, Frisoli A, Bergamasco M, Micera S Evaluation of the effects of the arm light exoskeleton on movement execution and muscle activities: a pilot study on healthy subjects. J NeuroEng Rehabil 13(1). https://doi.org/10.1186/s12984-016-0117-x

204. Vanezis A, Robinson MA, Darras N (2015) The reliability of the ELEPAP clinical protocol for the 3D kinematic evaluation of upper limb function. Gait Posture 41(2):431-439. https://doi.org/10.1016/j.gaitpost.2014.11.007

205. Jaspers E, Desloovere K, Bruyninckx H, Klingels K, Molenaers G, Aertbeliën E, Gestel LV, Feys H (2011) Three-dimensional upper limb movement characteristics in children with hemiplegic cerebral palsy and typically developing children. Res Dev Disabil 32(6):2283-2294. https://doi.org/10.1016/j.ridd.2011.07.038

206. Dounskaia N, Wang W (2014) A preferred pattern of joint coordination during arm movements with redundant degrees of freedom. J Neurophysiol (602):1040-1053. https://doi.org/10.1152/jn.00082.2014

207. Yan H, Yang C, Zhang Y, Wang Y Design and validation of a compatible 3-degrees of freedom shoulder exoskeleton with an adaptive center of rotation. J Mech Des 136(7). https://doi.org/10.1115/1.4027284

208. Gamage SSU, Lasenby J (2002) New least squares solutions for estimating the average centre of rotation and the axis of rotation. J Biomech 35(1):87-93. https://doi.org/ 10.1016/S0021-9290(01)00160-9

209. Cutti A, Parel I, Raggi M, Petracci E, Pellegrini A, Accardo A, Sacchetti R, Porcellini G (2014) Prediction bands and intervals for the scapulo-humeral coordination based on the Bootstrap and two Gaussian methods. J Biomech 47(5):10351044. https://doi.org/10.1016/j.jbiomech.2013.12.028

210. Ricci L, Formica D, Sparaci L, Lasorsa F, Taffoni F, Tamilia E, Guglielmelli E (2014) A new calibration methodology for thorax and upper limbs motion capture in children using magneto and inertial sensors. Sensors 14(1):1057-1072. https://doi.org/10.3390/s140101057

211. Pierrart J, Lefèvre-Colau M-M, Skalli W, Vuillemin V, Masmejean EH, Cuénod CA, Gregory TM (2014) New dynamic three-dimensional MRI technique for shoulder kinematic analysis. J Magn Reson Imaging 39(3):729-734. https://doi.org/10.1002/jmri.24204

212. El-Habachi A, Duprey S, Chèze L, Dumas R (2013) Global sensitivity analysis of the kinematics obtained with a multibody optimisation using a parallel mechanism of the shoulder. Comput Methods Biomech Biomed Eng 16(sup1):61-62. https://doi.org/10.1080/10255842.2013.815907

213. Pontin JCB, Stadniky SP, Suehara PT, Costa TR, Chamlian TR (2013) Static evaluation of scapular positioning in healthy individuals. Acta Ortop Bras 21(4):208-212. https://doi.org/10.1590/S1413-78522013000400005
214. Xu X, Lin J-H, Li K, Tan V (2012) Transformation between different local coordinate systems of the scapula. J Biomech 45(15):2724-2727. https://doi.org/10.1016/j.jbiomech. 2012.08.021

215. Xu X, Lin J-H, McGorry RW (2012) Coordinate transformation between shoulder kinematic descriptions in the Holzbaur et al. model and ISB sequence. J Biomech 45(15):2715-2718. https://doi.org/10.1016/j.jbiomech.2012.08.018

216. Izadpanah K, Weitzel E, Honal M, Winterer J, Vicari M, Maier D, Jaeger M, Kotter E, Hennig J, Weigel M, Sudkamp NP (2012) In vivo analysis of coracoclavicular ligament kinematics during shoulder abduction. Am J Sports Med 40(1):185-192. https://doi.org/10.1177/0363546511423015

217. Yang JJ, Feng X, Xiang Y, Kim JH, Rajulu S (2009) Determining the three-dimensional relation between the skeletal elements of the human shoulder complex. J Biomech 42(11):1762-1767. https://doi.org/10.1016/j.jbiomech.2009.04.048

218. Yang J, Feng X, Kim JH, Xiang Y, Rajulu S (2009) Joint coupling for human shoulder complex. Digit Hum Model 72-81. https://doi.org/10.1007/978-3-642-02809-0_9

219. Folgheraiter M, Bongardt B, Albiez J, Kirchner F (2009) Design of a bio-inspired wearable exoskeleton for applications in robotics. BIODEVICES 2009:414-421. https://doi.org/10.5220/0001550704140421

220. Cutti AG, Giovanardi A, Rocchi L, Davalli A, Sacchetti R (2008) Ambulatory measurement of shoulder and elbow kinematics through inertial and magnetic sensors. Med Biol Eng Comput 46(2):169-178. https://doi.org/10.1007/s11517-007-0296-5

221. Illyés Á, Kiss RM (2007) Shoulder joint kinematics during elevation measured by ultrasound-based measuring system. J Electromyogr Kinesiol 17(3):355-364. https://doi.org/10.1016/j.jelekin.2006.02.004

222. Illyés A, Kiss RM (2006) Method for determining the spatial position of the shoulder with ultrasound-based motion analyzer. J Electromyogr Kinesiol 16(1):79-88. https://doi.org/10.1016/j.jelekin.2005.06.007

223. Bobrowitsch E, Imhauser C, Graichen H, Dürselen L (2007) Evaluation of a 3D object registration method for analysis of humeral kinematics. J Biomech 40(3):511-518. https://doi.org/10.1016/j.jbiomech.2006.02.016

224. Dennerlein JT, Kingma I, Visser B, van Dieën JH (2007) The contribution of the wrist, elbow and shoulder joints to single-finger tapping. J Biomech 40(13):3013-3022. https://doi.org/10.1016/j.jbiomech.2007.01.025

225. Veldpaus F, Woltring H, Dortmans L (1988) A leastsquares algorithm for the equiform transformation from spatial marker co-ordinates. J Biomech 21(1):45-54. https://doi.org/ 10.1016/0021-9290(88)90190-X

226. De Sapio V, Holzbaur K, Khatib O (2006) The control of kinematically constrained shoulder complexes: physiological and humanoid examples. In: 2006 IEEE international conference on robotics and automation, pp 2952-2959. https://doi.org/10.1109/ROBOT.2006.1642150

227. Kang T, Tillery S, He J (2003) Determining natural arm configuration along reaching trajectory. In: 25th Annual international conference of the IEEE engineering in medicine and biology society, pp 1444-1447. https://doi.org/10.1109/IEMBS.2003. 1279599

228. Kang T, He J, Tillery SIH (2005) Determining natural arm configuration along a reaching trajectory. Exp Brain Res 167(3):352-361. https://doi.org/10.1007/s00221-005-0039-5

229. de Groot J, Brand R (2001) A three-dimensional regression model of the shoulder rhythm. Clin Biomech 16(9):735-743. https://doi.org/10.1016/S0268-0033(01)00065-1 
230. Endo K, Yukata K, Yasui N (2004) Influence of age on scapulo-thoracic orientation. Clin Biomech 19(10):1009-1013. https://doi.org/10.1016/j.clinbiomech.2004.07.011

231. Novotny JE, Beynnon BD, Nichols CE (2001) A numerical solution to calculate internal-external rotation at the glenohumeral joint. Clin Biomech 16(5):395-400. https://doi.org/10.1016/S0268-0033(01)00018-3

232. Baerlocher $P$, Boulic $R$ Parametrization and range of motion of the ball-and-socket joint. Def Avat 180-90. https://doi.org/10.1007/978-0-306-47002-8_16

233. Kamper DG, Rymer WZ (1999) Effects of geometric joint constraints on the selection of final arm posture during reaching: a simulation study. Exp Brain Res 126(1):134-138. https://doi.org/10.1007/s002210050723

234. Romkes J, Bracht-Schweizer K (2017) The effects of walking speed on upper body kinematics during gait in healthy subjects. Gait Posture 54:304-310. https://doi.org/ 10.1016/j.gaitpost.2017.03.025

235. Gutierrez EM, Bartonek Å, Haglund-Åkerlind Y, Saraste $\mathrm{H}$ (2003) Centre of mass motion during gait in persons with myelomeningocele. Gait Posture 18(2):37-46. https://doi.org/10.1016/s0966-6362(02)00192-3

236. Salmond LH, Davidson AD, Charles SK (2016) Proximaldistal differences in movement smoothness reflect differences in biomechanics. J Neurophysiol 117(3):1239-1257. https://doi.org/10.1152/jn.00712.2015

237. Monjo F, Forestier N (2016) Muscle fatigue effects can be anticipated to reproduce a movement kinematics learned without fatigue. Neuroscience 339:100-108. https://doi.org/ 10.1016/j.neuroscience.2016.09.042

238. Togo S, Kagawa T, Uno Y Uncontrolled manifold reference feedback control of multi-joint robot arms. Front Comput Neurosci 10. https://doi.org/10.3389/fncom.2016.00069

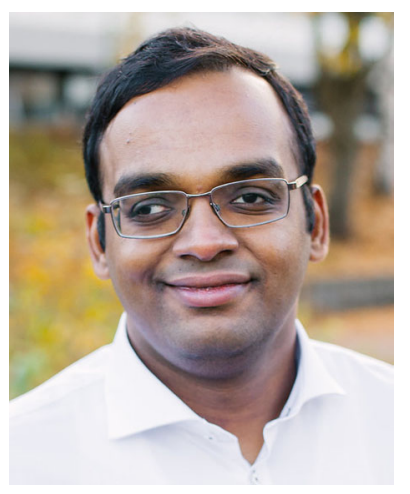

Rakesh Krishnan is a Doctoral Researcher at Robotics, Perception and Learning laboratory (RPL) and is affiliated to the BioMEx center, both at the KTH Royal Institute of Technology, Stockholm. He is a member of IEEE-RAS TC on Human Movement Understanding.

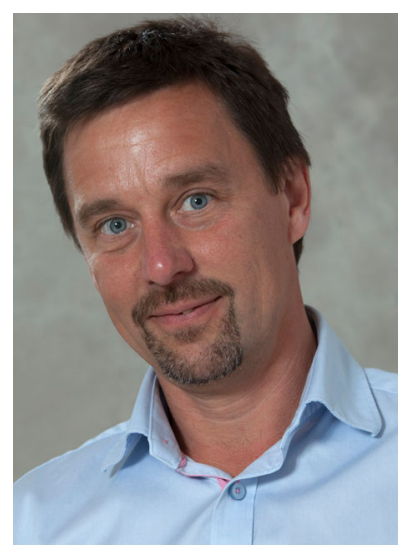

Niclas Björsell is an Associate Professor in the Department of Electronics and directs the Automation Engineering Program at the University of Gävle. He is also the Associate Editor of IEEE Transactions on Instrumentation and Measurement.

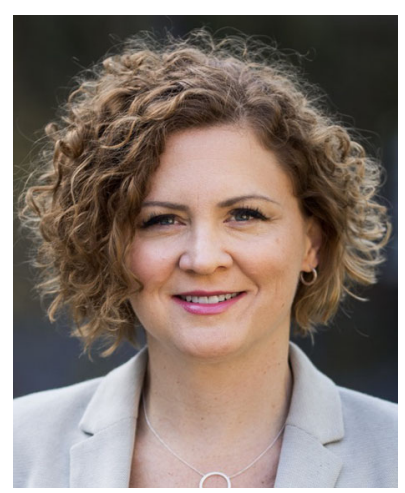

Elena M. Gutierrez-Farewik is an Associate Professor of Biomechanics and directs the BioMEx Center at KTH Royal Institute of Technology, Stockholm. She has a PhD in Orthopedics and a MSc in Biomedical Engineering.

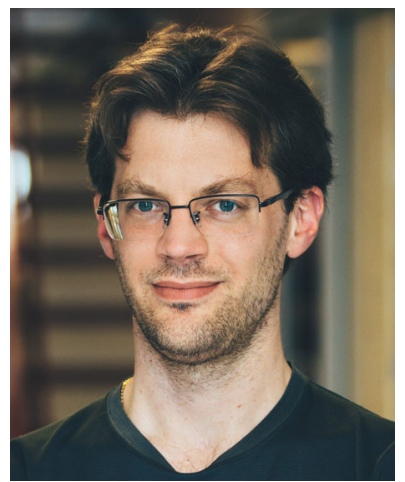

Christian Smith is an Assistant Professor at Robotics, Perception and Learning laboratory (RPL) and is affiliated to the BioMEx center, both at the KTH Royal Institute of Technology, Stockholm. His research interests include control and modelling for manipulation and grasping in human-centric environments and human-robot interaction. 